\title{
¿Observa el mercado español las relaciones laborales entre empresarios y sindicatos? Un análisis empírico para el mercado continuo *
}

\section{Spanish Stock Market observe labour relations between firms and Unions}

\author{
Ana María Sabater Marcos. Universidad de Alicante. \\ Joaquina Laffarga Briones. Universidad de Sevila.
}

\begin{abstract}
RESUMEN El objetivo de este trabajo es analizar la reacción del precio, volumen negociado y volatilidad de las acciones de las compañías cotzzadas en el mercado continuo español ante la firma de un convenio colectivo a nivel empresa. Teniendo en cuenta que este tipo de convenios sesga al alza los salarios respecto a los del sector, la hipótesis de partida es que un convenio de empresa incorpora información que podría considerarse de forma negativa por los inversores. Esto conllevaría la venta de los títulos de tal empresa y una caída en su precio. Por tanto, esperamos encontrar incrementos en ei volumen negociado acompañados de rendimientos negativos para estas empresas en torno a la fecha del acontecimiento. Los resultados generales de este trabajo confirman esta hipótesis, si bien se observan reacciones distintas dependiendo del sector al cual pertenezca la empresa. Por otro lado, la llegada de la nueva información que contiene la turma del convenio, podría afectar a la volatilidad específica de dichos rendimientos. Cabe esperar, según Ia variante de hipótesis tradicional de eficiencia de mercado, que si la nueva información reduce la incertidumbre sobre los fíujos futuros de las empresas que firman el convenio, la volatilidad especifica de las mismas sea menor a partir de esa fecha. Así ocurre con los datos de nuestra muestra.
\end{abstract}

PALABRAS CLAVE Rentabilidades Anormales, Volúmenes Anormales, Volatilidad, Convenio Colectivo de empresa.

\begin{abstract}
The objective of this paper is to observe the reaction of the Spanish Stock Market to the signature of a collective agreement at a company level, measuring abnomal returns, abnormal volume and the associated risk on the day the information reaches the market. Bearing in mind that this type of agreement tends to increase salaries with respect to those of the sector, the initial hypothesis is that a company agreement incorporates negative information with the expectation of abnormal negative returns and positive volume on the event day. The arrival of new information not only modifies the average expected performance of the group of companies concerned, but also affects performance volatility it is expected, according to the variant of the traditional hypothesis of market efficiency, that risk and expected performance will vary in the same direction, depending on the sign of the information on the company involved.
\end{abstract}

KEX WOBDS Abnormal Returns; Abnomal Volume; Volatility; Collective Bargaining.

() Los autores agradecen a Beièn ibieto Deménech y a Juan Luis iNicoiau Gonzálbez el tiempo dedicado a la realización de este trabajo asl como los comentarios y aportaciones efectuados al mismo. 


\section{INTRODUCCÓN}

La rentabilidad diaria de las empresas que cotizan en Bolsa está condicionada por determinadas fechas clave o eventos, como anuncios do pago de dividendos, ampliaciones de capital, fusiones y adquisiciones, que mercado e inversores tratan de internalizar para evitar los posibles efectos que estos anuncios tienen sobre los precios de los activos. La pregunta que se intenta responder en este rabajo es si los inversores, en particular, y el mercado en general, observan las relaciones laborales que entablan empresarios y sindicatos, es decir, si las relaciones laborales afoctan al valor de las empresas.

En concreto, este trabajo consiste en analizar si un evento laboral, como es la firma de un convenio colectivo de empresa, provoca movimientos en los precios de las acciones, en los volúmenes de negociación y en Ia volatilidad, en empresas del mercado español los días próximos al anuncio.

En el mercado de trabajo español la negociación colectiva contempla des niveles de negociación muy extendidos, el sectorial y el empresarial, y los resultados de la negociación son extensivos a todos los trabajadores ocupados independientemente de que estén afiliados a un sindicato. En primer lugar se negocia el convenio de sector, y de forma independiente la empresa puede desvincularse del mismo y pactar sus propias condiciones laborales y económicas. Fundamentalmente la negociación a nivel empresa, además de mejorar las condiciones económicas, proporciona a la empresa condiciones exclusivas para sus trabajadores, ya que existen sectores en los que conviven empresas muy diferentes (en términos de tamaño por ejemplo) y el convenio sectorial no siempre se adapta a todas ellas.

Jimeno y Rodriguez [1996], Bárcena e Inurrieta [1997], encontraron que las empresas con convenio colectivo propio, o de empresa, pagaban una prima salarial de alrededor del $5 \%$ frente a empresas de las mismas características pero que habian aceptado un convenio de sector. Es decir, un tzabajador que pertenece a una empresa con convenio propio cobra en media un $5 \%$ más que un trabajador de su misma categoría y de otra compañía acogida al convenio del sector.

La prima salarial que se produce en los convenios colectives firmados a nivel de empresa, aumenta los gastos de personal lo que, según ha mostrado la evidencia empirica previa para el mercàdo español, podría reducir el valor actual de los futuros fiujos de caja con la consecuente pérd̉ida de riqueza que supone para el inversor. Si esto es así y el inversor tiene en cuenta las relaciones laborales en general, y la negociación colectiva en particular, la firma de un convenio de empresa podría interpretarse como una mala noticia, con la consecuente caída del precio de las acciones de la empresa y mayores presiones de venta de los títulos afectados ante el anuncio. Ahora bien, si İ subida salarial se ve compensada con un aumento de Ia productividad, el evento podría no tener efecto alguno sobre el mercado bursátii.

La mayoría de evidencia existente ha detectado que las variaciones en los precios son negativas alrededor de la fecha de publicación del anuncio. Estos resultados han sido considerados como un claro indicio de contenido informativo en la información difundida con la publicación de la firma del convenio. 
bre la evolución de los fujos de tesorería futuros de la empresa, por lo que en un mercado eficiente, esto debe ir acompañado de una disminución del precio. La magnitud del exceso de rendimiento, volumen y volatilidad si lo hubiere, reflejará el incremento o decremento marginal que, sobre las variables de mercado, tiene la firma de un nuevo convenio de empresa.

Para contastar esta hipótesis, la primera cuestión que nos planteamos es si el everto laboral origina movinientos en los precios de las acciones y en el volumen de negociación. La segunda pregunta que nos hacemos es si el contenido informativo del evento modifica la volatilidad de los títulos. Y la última cuestión es si las reacciones en la negociación, volatilidad y precio están vinculadas con características especificas de las empresas que firman este tipo de convenio.

La principal contribución a este estudio se halla en el análisis de la reacción de mercado utilizando la reacción del volumen de negociación como medida complementaria de los cambios en los precios de las acciones ante un evento laboral.

Nuestros resultados muestran la presencia de rentabilidades anormales negativas y volumenes anormales positivos. En relación con la volatilidad, si nuestro evento incorpora información negativa para el mercado, es importante analizar su efecto sobre la volatilidad de los títulos, de modo que se observará si varía en la misma dirección que la rentabilidad o en sentido contrario. Todo va a depender del contenido informativo del evento. Si esta información reduce la asimetría informativa la volatilidad de los títulos disminuirá, es decir, la incertidumbre que sobre la evolución de la empresa tienen los inversores será menor a pesar de que consideren el evento como una mala noticia. Los resultados, analizando la volatilidad específica, corroboran el argumento anterior.

Por último, y después de establecer la existencia de reacciones diferentes en el precio, volatilidad y el volumen, se estudia si el cambio en las expectativas de los inversores, que provoca estas variaciones, se ve influenciado por determinantes de las compañías que firman un convenio de estas características, en términos de tamaño, resultado del ejercicio, shocks no anticipados en costes salariales, características propias del convenio y efecto sector.

El trabajo queda estructurado de la siguiente forma: en el segundo epígrafe se detalla la evidencia empírica, la recogida de datos y definición de variables quedan recogidos en el apartado tercero. En el cuarto, quinto y sexto se refieja la metodologia de análisis y los distintos resultados obtenidos en precio, volumen y volatilidad respectivamente. En la sección séptima se analiza si la respuesta de las variables de mercado es sensible a determinadas características de la empresa y del propio convenio y el apartado octavo recoge las conclusiones.

\section{EVIDENCIA EMPÍRICA PREVIA}

La literatura que analiza la relación entre negociación colectiva e información contable es muy prolifera y variada. Las distintas líneas de investigación tratan diversos temas, entre los que destacan, el análisis del papel de la información contable en el proceso de negociación [Morishira, 1991b] o por ejemplo, efectos potenciales de la negociación colectiva en las decisiones contables [Liberty y Zimmerman, 1986; Yamaji, 1986; DeAngelo y DeAn- 
gelo, 1991, y Cullinan y Knobiett, 1994]. Todos los trabajos se encuentran en el marco anglosajón y son de dificil aplicación al caso español, ya que la inmonsa mayoría de información con la que se żabaja en el ámbito interno en una negociación colectiva no es de obligada publicación en España. Aún así, la propia existencia de un convenio de empresa nos permite obtener conclusiones de interés, como veromos en este tiabajo.

Entre los trabajos que utalizan la metodología de estudio do eventos, se encuentran el de Ruback y Zimmerman [1984], Bronar's y Deere [1994] para ol mercado americano, obteniendo en ambos trabajos una disminución del valor bursátil en presencia de negociación en la empresa, y el de Abowd [1989] que encuentra que los shocks no anticipados en costes salariales reducen el valor bursítil en la misma proporción.

Otros trabajos que también estudian la relación entre negociación colectiva y rentabilidad empresarial para el caso anglosajón, son los de Salinger [1984], que midiendo la rentabilidad con ia $Q$ de Tobin encuentra una relación negativa entre presencia sindical y rentabilidad, o Connolly, Hirsch y Hirschey [1986], que obtienen que las empresas con un alto nivel de sindicación ven reducido su valor de mercado y sus inversiones en I+D.

A través de una regresión lineal entre distintas medidas de rentabilidad y negociación colectiva, Clark [1984] manifiesta que la negociación afecta a la distribución, pero no a la producción ni al uso de factores productives.

El trabajo más reciente que estudia la relación entre rentabilidad y negociación colectiva es desarrollado por Inurrieta [1997b] para el caso español. Al igual que Ios anteriores trabajos demuestra que la relación que existe entre la negociación colectiva en la empresa y su rentabilidad es negativa en torno a la fecha del evento.

El contenido informativo de numerosos eventos no sólo se mide analizando cambios en el precio de las acciones, sino también analizando el volumen de negociación. Aunque precios y volumen reflejan si el evento tiene contenido informativo, cada una de estas magnitudes captura aspectos diferentes de las reacciones de los inversores. Una distinción importante entre cambios en el precio y en el volumen de negociación de las acciones, como magnitudes de contenido informativo, es que la primera implica cambios en las expectativas del mercado en su conjunto, mientras que la segunda podría refiejar cambios en las expectativas de los inversores de forma individual. [Kim y Verrecchia, 1991a].

Bamber y Cheon [1995] señalan que cambios en volumen no tienen por qué venir acompañados de cambios en precios y viceversa. Si en la primera transacción se aícanza el consenso entre los inversores, se observarían cambios en precio pero no en volúmenes, asumiendo que las preferencias de riesgo entre los inversores son homogéneas. Pero si existe heterogeneidad, puede observarse cambios en volumen incluso después de haber alcanzado un precio de equilibrio.

Karpoff [1986], por su parte, indica que hay dos explicaciones que justifican por qué los eventos informativos afectan al volumen de negociación. La falta de consenso respecto a la interpretación de la información revelada conduce a un mayor volumen de negociación. A su vez, aunque se alcance un acuerdo, el volumen seguirá siendo mayor si los inversores tenían expectativas distintas previas al evento.

En lo que respecta a la evolución de la volatilidad asociada a los t́tulos cotizados y afecta- 
reducirá la incertidumbre que sobre la evolución de los beneficios de la empresa tienen los inversores [Brown et al., 1988].

En este trabajo tratamos de analizar estas tres variables: rentabilidad, volumen y volatilidad especifica anomales.

\section{MUESTRA Y DEFINICIÓN DE VARIABLES}

Nuestra muestra está compuesta por empresas del mercado continuo español que firman un convenio colectivo interprovincial y a nivel empresa entre 1995 y 2001.

En la primera etapa, y a partir de las empresas cotizadas en el mercado continuo que conforman la muestra, a través de una búsqueda exhaustiva en los $B O E$ desde el año 1995 al 2001, se recogieron todas aquellas fechas para las que aparecía publicado en el boleún la firma de un convenio colectivo de empresa ". De esta primera búsqueda se obuienen un total de 230 convenios para un total de 58 empresas. Se eligió como momento cero, es decir, día a partir del cual el mercado conoce el evento, la firma del texto articulado del colectivo, fecha que recoge el $B O E$.

A continuación, para corroborar que la fecha elegida como momento cero es la correcta, se efectú tuna segunda búsqueda de datos, concretamente, la fecha de publicación de este tipo de eventos en prensa económica y en la página Web de la Comisión Nacional del Mercado de Valores. Para ello se realiza la búsqueda correspondiente en los diarios de prensa Cínco Días y en la base de datos Baratz. De esta forma se detecta que el anuncio de acuerdo o firma de convenio, relativos a empresas de la muestra, se pubican el mismo día o el día posterior a la firma del texto articulado para la mayoría de empresas, lo que nos permite confirmar la validez de la fecha elegida como momento cero.

Con el objeto de contrastar cualquier conducta anormal en la rentabilidad de las acciones de estas empresas, en la siguiente etapa se selecciona la Iongitud de la eventana del suceson. En concreto, se consideran los cinco días previos y posteriores a la fecha de la noticia debido a que, aunque la mayoría de la información sobre convenios colectivos se suele incorporar rápidamente en el precio de las acciones, en ocasiones puede filtrarse antes de su publicación formal o bien retrasarse su manifestación. La tramitación de un convenio colectivo es sencilla, una vez se fima el texto articulado del convenio entre empresa y sindicatos (momento cero), el mismo debe registrarse en el Registro de Convenios de la Dirección General de Trabajo, registro de carácter púbíco. La media es de cinco días desale que se firma el acuerdo hasta su inscripción en dicho registro. Es lógico pues, que esta información sea pública como máximo cuando se inscribe en el registro. Además el mercado puede conocer la existencia del acuerdo pocos días antes de la firma, en caso de preacuerdo, ya que hacen eco de la noticia distintos medios de prensa.

Se eliminan de la muestra aquellas noticias en cuya «ventana del suceso» se publicaron determinados anuncios sobre otros hechos relevantes para la empresa, como fusiones, contratos con el gobieno, demandas juobiciales, ampliaciones de capital, declaración de dividendos, anuncio de beneficios, entre otros. Ello facilita la medición exclusiva del efecto de la firma de un nuevo convenio, y se elimina la posibilidad de incluir efectos confusos. Asi-

(1) Ver Apéndice. 
mismo, se excluyen aquellos sucesos en cuyo periodo de estimación do las rentabilidades anormales se publica otra noticia de firma 0 acuerdo de convenio.

Todo ello reduce la muestra de firmas de convenios a 96 eventos o firmas de convenios a nivel empresa, relativos a un total de 45 compañías.

\section{TABUA 1}

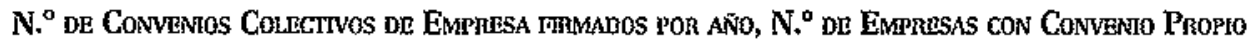
y N. ${ }^{\circ}$ DE EMPRISAS COMPETDORAS CON CONVENo de SECTOR

\begin{tabular}{|c|c|c|c|c|c|c|c|c|c|c|}
\hline SECTOR & 1995 & 1996 & 1997 & 1998 & 1999 & 2000 & 2001 & TOTAL & $\begin{array}{c}N^{\circ} d \theta \\
\text { empresas } \\
\text { C.C. } \\
\text { de empresa }\end{array}$ & $\begin{array}{c}N^{\circ} \text { de } \\
\text { empresas } \\
\text { G.G. } \\
\text { de sector }\end{array}$ \\
\hline AlUEVAS TECNOLOGIAS & 1 & 2 & 1 & 2 & 1 & 0 & 2 & $\theta$ & 3 & 3 \\
\hline $\begin{array}{l}\text { TRANSFORMACTÓN } \\
\text { DE METALES }\end{array}$ & 2 & 1 & 3 & 2 & 1 & 1 & 1 & 11 & 4 & 7 \\
\hline $\begin{array}{l}\text { JRANSPORIES } \\
y \text { COKAUNICAGIONES }\end{array}$ & 0 & 0 & 2 & 3 & 3 & 2 & 3 & 13 & 7 & 5 \\
\hline IsDUSTRI OUMACA & 3 & 1 & 1 & 0 & 1 & 0 & 0 & 6 & 3 & 2 \\
\hline $\begin{array}{l}\text { COMERCIO } \\
\text { Y OTAOS SERVICIOS }\end{array}$ & 2 & 2 & 1 & 2 & 0 & 1 & 1 & 9 & 3 & 8 \\
\hline $\begin{array}{l}\text { CEMENHO, VIDRO } \\
Y \text { MAYERIALES } \\
\text { OE CONSTRLCCHON }\end{array}$ & 4 & $t$ & 0 & 0 & 0 & 0 & 0 & 5 & 3 & 1 \\
\hline IMHOBILIABIAS & 2 & 0 & 0 & 0 & 0 & 0 & 0 & 2 & 1 & 9 \\
\hline $\begin{array}{l}\text { OTRAS WWUSTRAAS } \\
\text { OE TRANSFORMACION }\end{array}$ & 2 & 2 & 2 & 0 & $i$ & 1 & 2 & 10 & 4 & 18 \\
\hline ESEERGIA Y AGUA & 4 & 7 & 5 & 3 & 2 & 1 & 2 & 24 & 14 & 0 \\
\hline METALICAS BASICAS & 0 & 0 & 0 & 0 & 0 & 2 & 0 & 2 & 1 & 5 \\
\hline FinfANGIERAS & 1 & 1 & 1 & 0 & 1 & 1 & 0 & 5 & 2 & 14 \\
\hline TOTAL & 21 & 17 & 16 & 12 & 10 & 9 & 11 & 96 & 45 & 72 \\
\hline
\end{tabular}

La Tabla 1 recoge el número de empresas del mercado continue que tienen convenio propio y aquellas que durante el periodo muestral 1995-2001 se encuentran acogidas al con" venio del sector, ordenando por año los distintos eventos. Pedemos observar que existe una mayor presencia de convenios colectivos de empresa para las compañías de los sectores Transportes y Comunicaciones, Industria Química, Cemento Vidrio y Materiales de Construcción y Energía y Agua. De hecho, éste último es el único sector de la economía española que no tiene convenio de sector ya que todas las empresas del mismo poseen convenio propio o de empresa ${ }^{(2)}$. Para el resto de sectores, a excepción del sector Transformación de Metales que está muy equiparado, predomina la adhesión de las empresas al convenio de sector, siendo el caso más extremo el de las empresas financieras, sector

(2) Se observa que este sector acapara una parte importante dol total de convenios propios flimados, hecho que no afec- 
para el cual casi todas las empresas en el periodo muestral analizado estân acogidas al corivenio de sector.

Para estas empresas se recogen los datos de las rentabilidades y volúmenes negociados diarios de sus acciones. La muestra histórica de datos seleccionada corresponde al periodo de 2 de enero de 1995 a 31 de diciembre de 2001. Como representante de la cartera de mexcado se utiliza la del IBEX 35. La información fue obtenida de la base de datos SIBE.

Para contrastar la relación ente las magnitudes anormales de la empresa y sus características empresariales utilizamos, en primer lugar; variables dicotómicas de diferenciación sectorial. La clasificación por sectores se ha efectuado siguiendo la de la Comisión Nacional del Mercado de Valores. También se utilizan, para cada empresa, la variable tamaño, medido como el logaritmo de la capitalización bursátil, obtenido de la base de datos Compustat, la rentabilidad anual bursátil (Renbur), calculada capitalizando las rentabilidades mensuales obtenidas de $S I B E$ y como proxy de las expectativas de crecimiento utilizamos el ratio Market to Book (Market), calculado como la capitalización de mercado sobre los fondos propios consolidados.

Otxas variables empleadas en este estudio, cuyos datos han sido obtenidos de los infor. mes anuales auditados el año del convenio y el año anterior son: el número de empleados (Empleo); ingresos de explotación; resultado y margen de explotación y resuitado del ejercicio (Rdo); gastos de personal (GP) y variación en gastos de personal (Vargp); los gastos de personal por empleado y su variación (Varatio); Sorpresa o cambio inesperado en el coste laboral $[C t-E(C t)]$, siendo $E(C t)=C_{i-1} \cdot(1+g)$ la parte esperada del incremento salarial por empleado, donde $C_{t}$ es el coste salarial por empleado, y $g_{t}$ es la tasa de crecimiento media en los últimos cinco años de los salarios de cada empresa con convenio propio. La productividad contable (Ingresos de explotación-Consumo de mercaderías y de materias-Otros gastos de explotación) / Gastos de personal); el ratio de endeudamiento ((Total pasivo-Fondos propios) / Total pasivo); la solvencia a largo plazo [Pasivo total/ (Resultado antes impuestos + Dotaciones para amortiz. de inmovil. + Var: provis. tráfico y perd. créditos incob, + Var. prov. de inversiones financieras)] y la liquidez general o solvencia a corto plazo (Activo Circulante/ Pasivo Circulante). Por íltimo, en cuanto a las variables relativas al propio convenio, definimos la Productividad del Convenio (Produc. C.) como el porcentaje de convenios, dentro del sector 0 del grupo de empresas analizado, que incluyen algún tupo de cláusula relacionada con productividad, dato obtenido del texto del convenio publicado en el $B O E$ y la Tasa de Cobertura Sindical (TCS), que es el porcentaje de trabajadores cubiertos por convenio y empresa, construido con los datos del Registro de Convenios Colectivos. Cuando hablamos de variaciones en alguna de estas va. riables, se refiere al cambio que experimentan entre el año de la firma del convenio y el año anterior.

A continuación, desde un punto de vista descriptivo, veamos cuál es el cambio en algunas variables de interés para las empresas de la muestra agrupándolas por sectores. Las variables son: tamaño, market to book, rentabilidad bursátil, gastos de personal, coste salarial por empleado, resultados de explotación, resultado del ejercicio, número de enpleados, grado de endeudamiento y de solvencia. Los datos ofrecidos en la Tabla 2 representan la variación absoluta de las variables indicadas entre el año del convenio y el año anterior. 
Ana Maria Salratar Marcos y Joaqulina Lafrarta Briones ¿Obsorva el mercado español las roluciones laboraies ontro ormosesaios y sinłientes?

\section{TABLA 2}

\section{DIRERENGA DE DETERMANANTZS CONTABLES Y FANANCIRROS COSECUENCIA DEL EVTANTO}

En la Tabla se observan en términos medios y por sectores, las vartaciones experimentadas en algunas variables contables y financieras, antes y después do la firma del convenio. Se proporciona la significatividad del estadistico t de contraste.

\begin{tabular}{|c|c|c|c|c|c|c|c|}
\hline & $C V / M C$ & cYOS & 10 & $M B$ & $T M$ & $M T$ & 1 \\
\hline$N$ & 5 & 9 & 6 & 2 & 11 & 9 & 2 \\
\hline TAMASO & 15,46 & 72,50 & $-12,08$ & $-522,5$ & 112,79 & $-3,284$ & $-2,90$ \\
\hline REAQUA & $-0,032^{n *}$ & 0,026 & $-0,140^{\star *}$ & $-0,898^{\star \star}$ & $-0,087^{* *}$ & $-0,109^{* *}$ & $-0,097$ \\
\hline MARKET & $-0,120^{\star * *}$ & $0,684^{* *}$ & $-0,218^{* *}$ & $-0,225^{\star \star}$ & $-0,188^{* *}$ & $-1,506^{* * *}$ & 0,001 \\
\hline EMPLEO & 997,41 & $2394,55^{* *}$ & $-28,25$ & 28,00 & 64,10 & 90,77 & $-1,0$ \\
\hline WWARESO EXPLO & 72,14 & 59,46 & 85,81 & 778,77 & 293,80 & 10,01 & 14,31 \\
\hline RDO, EXPLO & 31,29 & 5,38 & 18,74 & 209,09 & 9,37 & $-6,38$ & 4,04 \\
\hline RoO. EJERC & 29,19 & 5,29 & 9,77 & 231,36 & 7,18 & $-7,77$ & $-2,97$ \\
\hline GTos. PERSONA & 4,37 & $31,06^{* *}$ & $12,99^{* *}$ & $37,44^{* *}$ & $10,52^{* \star}$ & $6,74^{* *}$ & 0,757 \\
\hline Gro. PERS./N. ${ }^{\circ} E_{M}$ & $2,75^{\star}$ & 0,888 & $9,5^{* *}$ & $2,00^{* *}$ & $2,27^{\star \star}$ & $3,11^{* *}$ & 1,00 \\
\hline Proovetinoad & 0,215 & $-0,017$ & $-0,287$ & 0,29 & 0,427 & $-0,145$ & $-8,93$ \\
\hline ENOEUDA. & $-7,087^{* * *}$ & $-1,251$ & $-7,432^{* *}$ & $-2,30^{*}$ & $2,344^{\star}$ & $-2,63^{* \pm}$ & $-5,99$ \\
\hline SolventatA $L P$. & $-0,080$ & $-0,017$ & $-0,815^{* *}$ & $-0,1100$ & 0,022 & $-0,001$ & 81,33 \\
\hline \multirow[t]{2}{*}{ SOLVENCIA $C P$} & $0,102^{* *}$ & 0,010 & $-0,000$ & 0,030 & $-0,064$ & 0,031 & 8,47 \\
\hline & OIT & $E Y A$ & $T Y C$ & TOTAL & & & FINAN \\
\hline TonaAín & $\begin{array}{c}10 \\
-21900\end{array}$ & $\begin{array}{c}24 \\
74708\end{array}$ & $\begin{array}{c}13 \\
-25.14\end{array}$ & $\begin{array}{c}91 \\
418.67\end{array}$ & \multicolumn{2}{|c|}{ TAMAAIOO. } & $\begin{array}{c}5 \\
541839\end{array}$ \\
\hline RENBUA & $-0,578^{* \star}$ & 0,006 & $-0,079$ & $-0,1099^{* *}$ & \multicolumn{2}{|c|}{ RENBUR } & $0,105^{*}$ \\
\hline MABKET & $-0,374^{* *}$ & 0,025 & $-2,049^{\star \star}$ & $-0,371^{\star \star}$ & \multicolumn{2}{|c|}{ MABKET BOOK } & 0,265 \\
\hline EMPLEO & 1113,15 & $1666,84^{\star *}$ & $4265,23^{* *}$ & $1400,03^{*}$ & \multicolumn{2}{|c|}{ EMPLEO } & 2919 \\
\hline WEAESO EXPLO & $-223,85$ & 1621,21 & $1820,02^{\star}$ & 774,76 & \multicolumn{2}{|c|}{ MGENEXPLOTAC. } & 486,71 \\
\hline RoO. EXPLO & 25,98 & 259,36 & 254,20 & 139,446 & \multicolumn{2}{|c|}{ RDO EJERCICIO } & 259,72 \\
\hline RDo. EJERC. & 25,71 & 130,04 & 119,86 & 77,91 & \multicolumn{2}{|c|}{ GTOS. PERSONAL } & $400,47^{\star \star}$ \\
\hline GTOS. PERSONA & $33,12^{\star *}$ & $70,31^{* *}$ & $171,62^{* *}$ & 70,74 & \multirow{2}{*}{\multicolumn{2}{|c|}{ GTOPERSO/EMPLEA }} & $12^{\star \star \star}$ \\
\hline Gro. PERS./N. ${ }^{\circ}$ Est. & 0,977 & $1,53^{\star \star}$ & $5,61^{\text {* }}$ & $3,57^{\star *}$ & & & \\
\hline PRODUCTIUDAD & 0,110 & 0,161 & $-0,031$ & $-0,009$ & & & \\
\hline ESOEUOA & $474^{*}$ & 0.993 & 2.089 & $-0,067$ & & & \\
\hline SOLVENCIA LP & 0.208 & 0.000 & $-0,358$ & 0.991 & & & \\
\hline SOLVESCIA CP & 0,022 & 0,053 & 0,154 & 0,141 & & & \\
\hline
\end{tabular}

Tamaño: Capitalización mercado Millones e; Renbur. Rentabilidad mercado anual. Market to Book. Capitalización de mercado sobre Fondos propios. Empleo. Número de empleados en el año de la firma del convenio. Gtos, personat. Gastos personal incluida SeguIldad Social. Míliones EUR. Gtos pers/n. em: Gastos personalfnúmero empleados. Mil eur. Ingreso, Resultado de explotación y Resultado dei ejercicio en Miliones de $\in$. Productividad: (ingresos de explotación-Consumo de mercaderlas y de materlas-Otros gastos de explotación)/Gastos de personal iúil Eur. Endeudamiento: (Total pasiwo-Fondos propios)/Total pasivo (\%). Capacidad devolución= liquidez L.p.: PasivoTotal/ (Rasultado Antes Impuestos+Dotaciones para amortiz de inmovll. + Vas. provis. tráfico y perd. créditos incob.+War. prov. de inversiones financieras). Liquidez general=Solvencia Corto: Activo CirculantefPasivo Circulante. IOE Industria Quimica, $C$ VOS = Comercio y Otres Servicios, $C V M C=$ Cemento, Vidrio y Materiales de Construcción, $l=$ Inmobiliarias, OIT= Otras Industrias de Transformación, $T Y C=$ Transportes y Comunicaciones, EYA= Energía y Aguta, FinAN= Financieras, MB= Metálicas Básicass, TM= Transformación de Metales, MT= Nuewas Tecnologias.

${ }^{* \star *}$ Significatiwo al $1 \% .{ }^{* *}$ Significativo al $5 \%$. * Significatlyo al $10 \%$.

Se observa que el tamaño disminuye para algunos de los sectores. Esa disminución indica que a finales del año del convenio, la valoración que hace el mercacio de las empresas que lo firman es menor que la valoración que hacía el año anterior a la firma. Este mismo resultado se observa si atendemos al signo negativo de la variable ratio market to book. Resulta llamativo el incremento en la capitalización bursátil observado para las empresas del 
prueba que esta elevada cifra se debe a que algunas empresas de este sector ampliaron capital el año de la firma del convenio.

Entre las condiciones laborales y económicas negociadas en los convenios, en ocasiones, se contempla un aumento de la productividad. En nuestra muestra, se observa que la misma disminuye o aumenta dependiendo del sector objeto de estudio, aunque en ambos casos, las variaciones no son significativas. Por tanto, parece que la negociación de un convenio de empresa no tiene consecuencias sobre esta variable. Los resultados obtenidos están en la línea de los de Abowd [1989] y Jimeno y Rodríguez [1996], que no encuentran aumentos significativos en los niveles de productividad. Además, Clark [1980] observa que el efecto sobre la productividad no es igual para todas las industrias ni en signo ni en magnitud, debido a distintos aspectos como la estructura de mercado y el grado tecnológico imperante en el sector. Para el caso español, Inumieta [1997a] encuentra que la productividad en el caso de empresas con negociación propia es menor que la de aquellas acogidas a un convenio de sector.

Las coincidencias más acusadas respecto a otros trabajos son los datos referidos a rentabilidades anuales. Inurrieta [1997a], Bronars et al [1994] y Clark [1984], con rentabilidades contables y de mercado anuales observan una relación negativa entre negociación colectiva y rentabilidad. En este trabajo se ha medido la rentabilidad bursátil anual a partir de la capitalización de las rentabilidades mensuales obtenidas de la Base de Datos SIBE. En la Tabla 2 se observa cue, en general, la rentabilidad de mercado disminuye el año de la firma del convenio, tal y como indica el signo negativo, a excepción de Energía y Agua, Financieras y Comercio y Otros servicios. Precisamente, en el caso del sector Energía y Agua que es el único que no dispone de convenio de sector, se produce un incremento tanto en la rentabilidad bursátil como en el ratio market to book, indicando que el convenio de empresa sería interpretado de forma positiva por los inversores cuando no existe convenio de sector. El sector de las financieras es el inverso; la práctica totalidad de las entidades in nancieras poseen un mismo convenio de sector, y también observamos cambios de signo positivo en rendimientos y ratio market to book, si bien, estos resultados podrían deberse a las características especiales de estas empresas ${ }^{(3)}$.

En cuanto al grado de endeudamiento y solvencia, la evidencia empírica argumenta que una de las estrategias que posee la empresa para intentar evadir el convenio colectivo es la emisión de deuda. La elección de estas variables para conocer las consecuencias de firmar un convenio de empresa tiene un fundamento tanto teórico como empírico. Existe abundante literatura que analiza la relación entre la negociación colectiva y la estructura de capital. Por un lado Bronars y Deere [1991] y Dalmazzo [1992], para el caso anglosajón, consideran que los accionistas tienen motivos estratégicos para emitir deuda, ya que de este modo aumenta la probabilidad de Quiebra y con ella un aumento en los costes de Ia misma, disminuyendo así el valor presente descontado de los beneficios futuros en el momento de la negociación, o lo que es lo mismo, las rentas que los sindicatos pueden tomar como base para la negociación ${ }^{(4)}$. Por tanto esperamos que el ratio de endeudamiento sea mayor (el año anterior a la firma) en aquellas empresas donde la probabilidad de que se lleve a

(3) Algunas variables para este sector se han omitido debido a la distinta normativa contable que ias regula, con la consiguiente imposibjilidad de comparación entre sectores.

(4) Nickell y Wadhwani [1988] establecen que el riesgo de quiebra en una empresa está relacionada con la estructura financiera de la misma. Si aumenta el nivel de deuda sobre el capital, presupone que las empresas pueden pagar menos salarios a sus trabajadores. 
cabo una negociación propia es mayor. Para el caso español, Inurrieta [1997] considera que la negociación colectiva on la empresa implica un mayor coste saiarial y un menor valor bursátil, y demuestra la existencia de una relación positiva ontro nivel de ondeudamiento y negociación colectiva a nivel empresa. Si se observa la Tabla 2, el ratio de endeudamiento disminuye de forma significativa para la mayoría de sectores y la liquidez es mayor después de la firma del convenio, corroborando la teoría anterior.

A pesar del aumento experimentado en los gastos de personal y en el coste por empleado, el resultado del ejercicio aumenta en media para la mayoría de sectores, a excepción de Inmobiliarias y Nuevas Tecnologías. Se ha de tener presente que son las empresas más grandes y con mejores resultados objetivos del sindicato para extraer un mayos volumen de rentas en una negociación interna. (Argumento utilizado por Jimeno y Rodríguez, 1996).

Por úlitimo, si agregamos todos los sectores, comprobamos que las empresas son menos valoradas por el mercado y los gastos de personal aumentan, al igual que el salario por empleado. El número de empleados aumenta de un año a otro, pero su salario crece aún más. La productividad es sensiblemente menor, to que junto al aumento en los gastos de personal nos demuestra que la creencia del inversor acerca de interpretar como pesimista el anuncio está fundamentado. La estrategia de la empresa de aumentar la emisión de deuda intentando evadir la negociación se muestra en el signo negativo del ratio de endeudamiento, lo que se corrobora por la mayor liquidez de la que dispone la empresa el año del convenio.

\section{EFECTO SOBRE EL PRECIO}

\subsection{Metodologta}

Como hemos expuesto en la introducción, el objetivo que pretendemos con ese trabajo es contrastar si la negociación colectiva al nivel de empresa repercute tanto en la rentabilidad y volumen negociado como en la volatilidad de la misma. Para ello, se va a utilizar la técnica Event Study o Estudio de Eventos ${ }^{(5)}$.

Dado que el precio de las acciones refieja el verdadero valor de la empresa y cambia inmediatamente en respuesta a cualquier acontecimiento que afecte potencialmente a los flujos de tesorería futuros de la empresa, podemos medir el impacto sobre el valor de la empresa de un determinado evento observando el cambio de precio de sus acciones en un periodo de tiempo muy corto en torno a la fecha en que tiene lugar. La primera variable a considerar en este estudio es la rentabilídad anormal en tomo a la fecha de la firma del convenio. Para su cálculo, usamos como rentabilidad normal la implicada por el modelo de mercado(6).

$$
R_{i t}=\alpha_{i j} \cdot \beta_{i} R_{m i}+\varepsilon_{i t}
$$

Donde $R_{i t}$ es la rentabilidad de la empresa $i$ en el día $t ; R_{m i}$ es la rentabilidad de la cartera de mercado en el día $t$; ai es rentabilidad esperada de la empresa $i$ que es independiente

(5) Para más informactón acerca de la metodologia Event Study consultar Fama,Fisher, Jensen y Roll [1969], Ball, y Brown [1968], Peterson [1989], Neumann [1980] y Schwert [1981].

(6) Como análisis átternativo de la estimación de las rentabilidades anormales, se ha considerado como rentabilidad de referencia la de una cartera de control compuesta por empresas del mismo sector pero que no firman convenio propio. Los 
del mercado; $\beta_{i}$ es la sensibilidad de la rentabilidad de la empresa $i$ a las variaciones en la rentabilidad del mercado; y $\varepsilon_{i l}$ es una perturbación aleatoria ${ }^{(7)}$.

La estimación de esta ecuación permite calcular las rentabilidades anormales diarias $\left(R A_{i}\right)$ para una noticia de la empresa $i$ :

$$
R A_{i t}=R_{i t}-\left(a_{i}+b_{i} R_{m u}\right)
$$

Donde $a_{i}$ y $b_{i}$ son las estimaciones $M C O$ obtenidas en las regresiones (1) usando un periodo precedente de 145 días al suceso, periodo de tiempo apropiado para la estimación de los coeficientes según la evidencia empírica sobre estudio de eventoss ${ }^{(3)}$. Los parámetros se es* timan por $M C O^{(9)}$.

Las rentabilidades anormales de los activos se promedian en sección cruzada cada día del periodo de acontecimiento o ventana de estudio, obteniendo la rentabilidad anormal media diaria, $R A_{t}=N^{-1} \sum_{i=1}^{N} R A_{i t}$

Ante la posibilidad de que el mercado anticipe la información del evento o se produzcan retardos en el precio de las acciones se emplea un periodo de evento de once días, centrado en torno a la fecha de la firma del convenio de empresa, desde el día $T_{1}=-5$ hasta el día $T_{2}=+5$. Para un análisis más completo, se calculan las rentabilidades anormales acumuladas en un periodo $\left(t_{1}, t_{2}\right)$, con el tin de conocer el efecto acumulado del suceso.

$$
R A A\left(t_{1}, t_{2}\right),=\sum_{l=t_{1}}^{t_{2}} R A_{t}
$$

Si la firma del convenio de empresa transmite nueva información a los inversores, el valor esperado de estas rentabilidades anormales debe ser significativamente distinto de cero. Para contrastar si el evento tiene contenido informativo en el mercado se utiliza el test de Boehmer et al. [1991] y también un test convencional que asume varianza constante entre activos. Estos tests paramétricos requieren el cumplimiento de la hipótesis de normalidad de la distribución de las magnitudes anormales. Sin embargo, un análisis del comportamiento de las rentabilidades anormales en la ventana de evento, indica que su distribución está ligeramente sesgada y presenta lepto-kurtosis. De hecho, el test de Jarque-Bera no valida la hipótesis de normalidad. Por ello, los resultados anteriores deben ser corroborados por un test no paramétrice que sea robusto en ausencia de normalidad como es el test de los Signos. Esta técnica está basada en el signo de la magnitud anormal, y requiere que las mismas sean independientes entre activos. Esto es, es un test binomiai de si la frecuencia de residuos positivos es igual a $0,5^{(10)}$.

(7) El estudio se ha realizado con carteras de control en lugar de la cartera de mercado, obtentendo los mismos resultados.

(8) Para los convenios firmados en los primeros meses del año 1995 se han utilizado rentabilidades diarias correspondientes al año 1994 con el fin de completar el periodo de estimación de 145 días anteriores a la ventana de evento.

(9) Los parämetros a y $\beta$ también han sido estimados con la técnica no paramétrica de Theil obteniendo los mismos resultados. Además, en un estudio alternativo se ha observado que no existe cambio en el riesgo sistemático como consecuencia del evento.

(10) Entre los meses de febrero y noviemore se firman el $92,7 \%$ de los convenios y el $89,5 \%$ de los mismos se firman Martes, Mlércoles y Jueves, por tanto parece poco probabie que nuestros resultados se vean afectados por el comportamiento estacional de los rendimientos de las acciones en enero y Lunes. 
El estadístico de contraste es la proporción observada de rentabilidades anormales positivas menos 0,5 , dividido por la desviación estándar de la distribución binomial y se distzibuye asintóticamente como una Normal ${ }^{(1)}$.

$$
S=\left[\frac{n}{N}-0,5\right] \frac{N}{0,5} \approx N(0,1)
$$

Donde $n$ es el número do casos con signo positivo y $N$ el número total de casos.

Para analizar la robustez de los resultados obtenidos a través del estudio de eventos, hemos incorporado a la metodología clásica un filțo altemativo en lo que respecta a la identificación de las rentabilidades anormales económicamente significativas ${ }^{123}$. Para ello, se consideran rendimientos atípicos aquelias rentabilidades anormales que se encuentran fuera de una horquilla creada, siendo los límites de la horquilia, dos veces por encima y por debajo la desviación típica de las rentabilidades anormales calculadas en un periodo precedente de 145 días al suceso. Tomamos como rentabilidad normal para el cálculo de las rentabilidades anormales, el modelo de mercado sin têrmino constante, una vez obtenidas las rentabilídades anormales consideramos significativas aquellas que se encuentran fuera de la horquilla y contrastamos la significatividad de los rendimientos anormales seleccionados con el test no paramétrico de Signos. Los resulitados se mantienen respecto a la metodología clásica.

\subsection{Resultados}

La evidencia hallada en el análisis de cambios en los precios de las acciones es que la publicación de la firma de un convenio de empresa tiene efecto informativo para los inversores. En la Tabla 3, se presentan los resultados de los test de significatividad de las rentabilidades anormales.

En el primer panel se recogen las rentabilidades anormales diarias paśa cada día de la ventana de evento $(-5,+5)$, así como en la tercera, cuarta y quinta coliunna los estadísticos del contraste que asume varianza constante entre activos, de Boehmer et $a l$. [1991] y el test de los Signos respectivamente ${ }^{(13)}$.

Como vemos, los cambios más significativos en las rentabilidades ocurren el día de la firma del convenio y el inmediatamente anterior. La rentabilidad anormal media del día del evento es de $-0,28 \%$, y los estadísticos de varianza constante entre activos, Boehmer y Signos toman el valor $-1,71,-1,74$ y $/ 1,73 /$ respectivamente, todos ellos significativos. Ĺa rentabilidad anormal media del día previo al anuncio su valor es del $-0,20 \%$ también es negativa y significativa sólo para Signos. La mayor caída en el precio se observa en el día +2 con un valor de $-0,34 \%$ significativo sólo para los contrastes paramétricos. Los resultados anteriores han sido corroborados aplicando la técnica no paramétrica bootstrap y la significatividad de los rendimientos anomales diarios alcanzan un nivel de significatividad del $5 \%$ y $1 \%$ para los días -1 y 0 respectivamente.

(11) Este test es $\frac{\rho-0,5}{\sqrt{\frac{\rho(t-\rho)}{N}}}$ dado que $p=1-p y$ que $\rho=0,5$, en el deneminador se sustituye este producto por $p^{2}=0,5^{2}$. 


\section{TABLA 3}

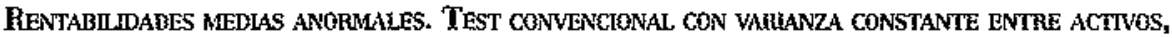
BOEHMER, Y SigNOS

\begin{tabular}{|c|c|c|c|c|}
\hline DIA. & $R A$ & Var cte & Boehmer & Signos \\
\hline $\begin{array}{l}-5 \\
-4 \\
-3 \\
-2 \\
-1 \\
0 \\
1 \\
2 \\
3 \\
4 \\
5\end{array}$ & $\begin{array}{l}-0,0031 \\
0,0004 \\
0,0005 \\
0,0019 \\
-0,0020 \\
-0,0028 \\
-0,0016 \\
-0,0034 \\
-0,0001 \\
-0,0030 \\
-0,0006\end{array}$ & $\begin{array}{c}-1,3081 \\
0,2727 \\
0,2286 \\
1,0967 \\
-1,0092 \\
-1,7194^{*} \\
-1,0842 \\
-2,1530^{*} \\
-0,0919 \\
-1,6733^{*} \\
-0,2850\end{array}$ & $\begin{array}{c}-0,8264 \\
-0,0216 \\
0,1904 \\
1,5298 \\
-0,7221 \\
-1,7424^{*} \\
-1,2548 \\
-1,7442^{*} \\
0,1142 \\
-0,9613 \\
-0,5667\end{array}$ & $\begin{array}{c}/ 1,5309 / \\
10,7144 / \\
10,1020 / \\
10,3061 / \\
/ 1,9391 /{ }^{*} \\
/ 1,7350 / \\
/ 1,3268 / \\
/ 1,5309 / \\
/ 1,1226 / \\
/ 0,9185 / \\
/ 1,1226 /\end{array}$ \\
\hline Intervalo & $R A A$ & VAR. CTE & BOEHMER & SIGNOS \\
\hline $\begin{array}{l}(-5,+5) \\
(-2,+2) \\
(-1,+1) \\
(-5,-4) \\
(-5,-3) \\
(-5,-2) \\
(-5,-1) \\
(-4,-3) \\
(-4,-2) \\
(-3,-1) \\
(-2,0) \\
(-1,0) \\
(0,+1) \\
(0,+2) \\
(+1,+2) \\
(+1,+3) \\
(+1,+5) \\
(+2,+3) \\
(+2,+4) \\
(+3,+5)\end{array}$ & $\begin{array}{l}-0,0136 \\
-0,0136 \\
-0,0065 \\
-0,0027 \\
-0,0021 \\
-0,0002 \\
-0,0022 \\
-0,0010 \\
-0,0030 \\
0,0005 \\
-0,0029 \\
-0,0048 \\
-0,0044 \\
-0,0079 \\
-0,0051 \\
-0,0052 \\
-0,009 \\
-0,0036 \\
-0,0067 \\
-0,0039\end{array}$ & $\begin{array}{c}-2,3036^{\star *} \\
-3,2482^{\star \star *} \\
-2,5784^{\star \star *} \\
-0,8881 \\
-0,5463 \\
-0,0419 \\
-0,4258 \\
0,3558 \\
0,7996 \\
0,1338 \\
-1,1299 \\
-2,1776^{* *} \\
-1,8285^{\star} \\
-2,5852^{\star \star \star} \\
-2,2351^{\star \star} \\
-1,9564^{\star *} \\
-2,4452^{\star \star \star} \\
-1,6653^{\star} \\
-2,4564^{\star \star *} \\
-1,2175\end{array}$ & $\begin{array}{c}-2,0135^{* \star} \\
-3,0865^{\star * *} \\
-2,8455^{\star * *} \\
-0,6494 \\
-0,3437 \\
0,3153 \\
-0,0879 \\
-0,6494 \\
0,7833 \\
0,2998 \\
-1,0411 \\
-2,3364^{* *} \\
-1,8196^{\star} \\
-2,3129^{* *} \\
-1,9625^{\star *} \\
-1,6206 \\
-2,0591^{* *} \\
-1,1719 \\
-1,5595 \\
-0,8568\end{array}$ & 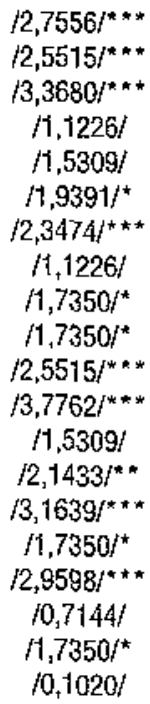 \\
\hline
\end{tabular}

* Significativo al $10 \%$.

** Significativo al 5\%.

**A Significattwo al $1 \%$.

La presencia de rentabilidades anormales negativas antes del día del evento parece indicar que se produce filtración de información a través de otras fuentes alternativas (como por ejemplo, información on-line) y, consecuentemente, los inversores anticipan el contenido informativo del evento laboral.

En el segundo panel de la Tabla 3, se resume el comportamiento del precio de las acciones a través de distintas ventanas alrededor del evento de forma acumulada.

La rentabilidad anormal media acumulada en la ventana de evento $(-5,+5)$ es de $-1,36 \%$ altamente significativa para todos los contrastes aplicados. El mismo resultado se observa para $(-2,+2)$ y $(-1,+1)$. Asimismo, se observan rentabilidades anormales negativas y significativas en ventanas pre-evento, como por ejemplo $(-5,-1)$ con un $p$-valor de $/ 2,34 /$, pa- 
ra el contraste no paramétrico de Signos, o ventanas post evento como $(+1,+5)$ significativa para todos los contrastes. Si se atiende al valon de las rentabilidades medias anormales acumuladas, se observa que el valor más pequeño, es decir, el periodo en el que los títulos son más penalizados es el comprendido entre el día -1 y el día +2 . La rentabi* lidad anormal media acumulada para la ventana $(-2,0)$ es de $-0,29 \%$, de $-0,48 \%$ para ($1,0)$ y la mayor bajada para la ventana $(0,+2)$ con una caída del $-0,79 \%$, todas ellas significativas para Signos. Si agregamos mayor número de días en la ventana, se observa que la caída en el precio es mayor para las ventanas post evento como por ejemplo $(+1,+5)$ que para la ventana $(-5,-1)$.

La filtración de información antes del momento cero, tal y como evidencian las ventanas pre-evento de rentabilidades referentes a los periodos $(-1,0),(-2,0)$ y $(-5,-1)$, por ejemplo, posiblemente son debidas a que en algunas negociaciones, pocos días antes de la firma del convenio colectivo y mientras se perfila el texto del mismo, se llega a un preacuerdo entre sindicato y empresa, del que puede hacer eco cualquier medio de información. Esto explicaría que el mercado empiece a reaccionar antes de la fecha del evento ante la liegada de nueva información.

Los resultados observados son consistentes con la evidencia previa detectada en otros trabajos [Ruback y Zimmerman, 1984, para el mercado anericano; Inumieta, 1997, para Bolsa de Madridl.

El estudio se ha realizado para una ventana de evento más amplia, concretamente $(-30,+30)$ días, no apreciándose ningún cambio significativo al margen del mostrado en la ventana $(-5,+5)$. Así, de forma gradual y en los días siguientes a la firma, el mercado incorpora esta información a sus títulos. Siendo la ventana elegida de suma importancia, ya que la mayoría de las rentabilidades anormales negativas son significativamente distintas do cero en la misma, lo que nos lleva a admitir la eficiencia del mereado español pero en sentido semifuerte.

La presencia de rendimientos anormales acumulados negativos y significativamente distintos de cero, indica que los inversores de forma homogénea interpretan el contenido informativo del evento como una mala noticia, e incorporan la información a sus títulos en los días siguientes a la firma del convenio colectivo de ernpresa.

\section{EFECTO SOBRE VOLUMEN DE NEGOCIACIÓN}

\subsection{Metodología}

En este apartado se analiza el efecto que el evento laboral tiene sobre el volumen de negociación diario de las acciones. En la literatura son varios los modelos utilizados para estimar los volúmenes de negociación anomales alrededor de un evento. El modelo ajustado al mercado seguido por Atiase y Bamber [1994]; el aplicado por Kross et al. [1994] que mide el volumen de negociación anormal ajustado a la mediana del volumen de la empresa específica o Bamber [1986] que mide el volumen de negociación anormal utilizando la mediana del volumen en el periodo de análisis de cada empresa. En esta investigación se 
cular el volumen de negociación anormal utilizando la media del volumen en el periodo de estimación de cada empresa.

Por lo que respecta al volumen anormal y observado para cada día $t$ y para cada título $i$, comparamos el capital negociado o volumen observado de cada día para cada empresa alrededor de la firma del convenio $\left(V_{t}\right)$, con una media del capital negociado en un periodo de 145 días anteriores a la ventana de evento como volumen esperado ${ }^{(14)}$.

$$
\begin{gathered}
v_{t t}=\operatorname{Ln}\left(1+V_{i t}\right) \\
\bar{V}_{i d}=\frac{\sum_{i=1}^{145} \operatorname{Ln}\left(1+V_{i i}\right)}{145}
\end{gathered}
$$

Siendo $V_{t t}$ la transformación logarítmica del volumen observado, $\bar{V}_{t}$ el volumen esperado.

El volumen de negociación anormal del activo $i$ en el día $t$ del periodo de acontecimiento, es el exceso del volumen observado sobre el estimado según la ecuación (6),

$$
V A_{i t}=V_{i t}-\bar{V}_{i t}
$$

Los volúmenes anormales de los activos se promedian en sección cruzada cada día de la ventana de estudio, obteniendo el volumen anormal medio diario, $V A_{i}=N^{3} \sum_{i=1}^{N} V A_{i k}$.

Se analizan los excesos de volúmenes de negociación acumulados en distintos intervalos en torno a la fecha de la firma del convenio de empresa para completar el análisis, y poder captar una posible anticipación o retraso en el contenido informativo derivado del evento laboral. La expresión de los mismos es la siguiente:

$$
V A A\left(t_{1}, t 2\right)=\sum_{i=t_{1}}^{t_{2}} V A_{t}
$$

Para contrastar la presencia de volúmenes anormales motivados por el evento, se aplica un test convencional que asume varianza constante entre actives, otro test paramétrico robusto a heterocedasticidad como Boehmer et al. [1991] y otro no paramétrico robusto en ausencia de normalidad en la distribución de los volúmenes anormales como por ejemplo el test de los Signos.

\subsection{Resultados}

En el primer panel de la Tabla 4, se presentan los resultados de los test de significatividad de los volúmenes anormales diarios para la ventana de evento.

(14) La transformación de las variables con logaritmos suaviza el problema de no normalidad. 
TABLA 4

VOLUMENES MEDIOS aNORMALES. TEST CONVENCIONAL CON VARIANZA CONSTANTE ENTRE ACTTNOS, BOLIMER Y SIGNOS

\begin{tabular}{|c|c|c|c|c|}
\hline DíA. & $R A$ & Var. Cte & Boehmer & Signos \\
\hline $\begin{array}{l}-5 \\
-4 \\
-3 \\
-2 \\
-1 \\
0 \\
1 \\
2 \\
3 \\
4 \\
5\end{array}$ & $\begin{array}{c}0,3674 \\
0,5419 \\
0,3834 \\
-0,3382 \\
0,1753 \\
0,4395 \\
0,0399 \\
-0,1177 \\
0,1185 \\
-0,3121 \\
-0,0678\end{array}$ & $\begin{array}{c}2.9054^{* * *} \\
3.2299^{* * *} \\
1.8392^{*} \\
-1.1795 \\
0.9548 \\
2.6117^{* * *} \\
0.1669 \\
-0.5550 \\
0.4550 \\
-1.0233 \\
-0.2417\end{array}$ & $\begin{array}{c}0.9786 \\
2.1401^{* *} \\
1.9277^{*} \\
-1.0258 \\
0.6645 \\
2.3940^{* * *} \\
0.2778 \\
0.3118 \\
0.0097 \\
-1.2814 \\
-1.1663\end{array}$ & $\begin{array}{c}10,3061 / \\
12,3474 /^{* * *} \\
11,5309 / \\
10,1020 / \\
10,1020 / \\
71,9391 / /^{*} \\
11,5309 / \\
10,9185 / \\
12,7556 /^{* * *} \\
10,9785 / \\
10,1020 /\end{array}$ \\
\hline Intervalo & $V A A$ & VAR. CTE & BOEHMER & SIGNOS \\
\hline $\begin{array}{l}(-5,+5) \\
(-2,+2) \\
(-1,+1) \\
(-5,-4) \\
(-5,-3) \\
(-5,-2) \\
(-5,-1) \\
(-4,-3) \\
(-4,-2) \\
(-3,-1) \\
(-2,0) \\
(-1,0) \\
(0,+1) \\
(0,+2) \\
(+1,+2) \\
(+1,+3) \\
(+1,+5) \\
(+2,+3) \\
(+2,+4) \\
(+3,+5)\end{array}$ & $\begin{array}{c}1,2302 \\
0,276 \\
0,654 \\
0,9094 \\
1,2929 \\
0,9542 \\
1,1295 \\
0,9254 \\
0,5867 \\
0,2782 \\
0,2761 \\
0,6148 \\
0,4787 \\
0,3615 \\
-0,0789 \\
0,0408 \\
-0,3388 \\
0,0016 \\
-0,3107 \\
-0,2608\end{array}$ & $\begin{array}{c}1,0335 \\
0,2831 \\
1,5043 \\
3,703^{\star * *} \\
3,3795^{\star * *} \\
1,8515^{\star * *} \\
1,9726^{\star *} \\
2,7813^{* * *} \\
1,2204 \\
0,5038 \\
0,7794 \\
2,2222^{* *} \\
1,5892 \\
0,95 \\
-0,2246 \\
0,0792 \\
-0,4081 \\
0,0044 \\
-0,5286 \\
-0,3813\end{array}$ & $\begin{array}{c}0,2786 \\
-0,1688 \\
1,3024 \\
1,8583^{*} \\
2,229^{\star *} \\
1,2143 \\
1,1914 \\
1,8583^{\star} \\
1,1236 \\
0,6192 \\
0,6922 \\
1,7331^{*} \\
1,4363 \\
1,1692 \\
0,3375 \\
0,2232 \\
-0,6621 \\
0,1517 \\
-0,5647 \\
-0,8996\end{array}$ & 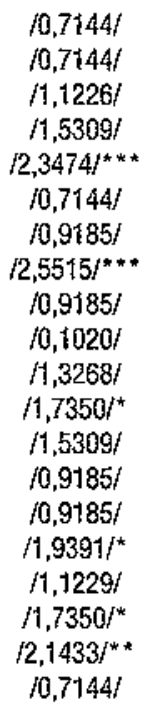 \\
\hline
\end{tabular}

* Significativo al $10 \%$.

** Significativo al $5 \%$.

** Significativo al $7 \%$.

Los cambios más significativos en los volúmenes anormales de negociación se observan en los días $-4,0$ y 3 para el contraste de los Signos, con unos incrementos después de deshacer la transformación logarítmica del $71,60 \%, 55,19 \%$ y $12,60 \%$ respectivamente. De acuerdo con Beaver [1968], Karpoff [1986] y Bamber y Cheon [1995], la presencia de un mayor volumen de negociación anterior al anuncio del evento, indica que existe heterogeneidad en las expectativas de los inversores individuales además de asimetría informativa. Esta heterogeneidad surge como consecuencia de las diferencias en las preferencias y en el tipo de información adquarida con anterioridad a la llegada de la noticia al mercado. Esta ausencia de honoggeneidad en las expectativas de los inversores provoca una reacción individual de los mismos que se refleja en cambios en los volúmenes de negociación. Esto 
Hasta que los inversores dejen de diferir en la forma de interpretar la información aparecen volúmenes anormales positivos y auseneia de rentabilidades anormales. En nuestro caso, se observa que el consenso se alcanza en el día anterior al evento y las rentabilidades anormales negativas junto con volúmenes anormales positivos en el momento cero indican que esa caída en el precio se debe a presiones de venta de los títulos ante la interpretación del evento como una mala noticia.

En cuanto a la presencia de volúmenes anormales positivos en el día tres de la ventana, Morse, 1981; Karpoff, 1986, y Bamber, 1987, sugieren que los volúmenes altos persisten durante los cinco días después del anuncio del evento, aún después de ajustarse el precio, debido a que, algunos inversores llegan tarde a la nueva información y ajustan sus carteras ignorando el hecho de que su información es obsoleta.

Mediante la utilización de los volúmenes anormales acumulados podemos ver el efecto de la firma o acuerdo del convenio colectivo a nivel empresa a través de distintas ventanas, ya que, como se observa en la Tabla 4, los volúmenes anormales son significativamente distintos de cero en distintos días. El efecto acumulado del suceso se observa en el segundo panel de la Tabla 4.

Para el intervalo $(-5,-3),(-4,-3)$ y $(-1,0)$, se producen cambios en el volumen promedio acumulado positivos y significativos del $263 \%, 150 \%$ y $84,04 \%$ respectivamente para todos los contrastes aplicados. Se observa que los mayores volúmenes de negociación se producen antes de la fecha de la firma del convenio, supuestamente este hecho viene provocado por desacuerdo en la interpretación de la información cuando la conoce el mercado, o por la presencia de inversores con expectativas heterogéneas previas aún cuando la información se interpreta de forma homogénea. A partír del momento cero, las ventanas post evento son poce significativas para el test de Signos, con sólo dos ventanas $(+1,+3)$ y $(+2,+3)$ que reflejan aumentos del $4,08 \%$ y $0,16 \%$ respectivamente, e incluso volúmenes anornales negativos en la ventana $(+2,+4)$ para Signos. El mayor volumen de negociación se produce hasta la firma del convenio, a partir de entonces se reduce de forma significativa. Se produce una disminución paulatina del volumen anormal de negociación conforme nos alejamos de la firma del convenio.

Los resultados indican que el exceso de volumen de negociación durante los días anteriores a la firma del convenio, reflejan de nuevo que el evento tiene contenido informativo para el inversor, pero el mercado difiere en la forma de interpretar la información, de ahí la presencia de volúmenes anormales positivos y ausencia de movimientos en los precios. A partir del día anterior al evento, el exceso de capital negociado junto a la caída en los precios, indican mayor presión de venta en los títulos afectados por el convenio por la interpretación negativa del evento que realiza el mercado.

\section{EFECTO SOBRE LA VOLATMIDAD}

\subsection{METODOLOGIA}

En cuanto a la volatilidad, Brown et al. [1988] documentan que la llegada de nueva información, positiva o negativa, tiende a aumentar o disminuir tanto el rendiniento esperado come la incertidumbre asociada a un título concreto. Si observamos una reducción de la misma supondría que la nueva información reduce la incertidunabre que sobre la evolución 
de los beneficios de la empresa tienen los inversores. Para llevar a cabo este análisis comparamos la rentabilidad anormal al cuadrado para cadia título $i$ como proxy de la varianza especiffica de cada empresa en cada día de la ventana de evento, con una media de las rentabilidades anomales al cuadrado estimadas en un periodo precedente de 145 días para cada tútulo $i$.

$$
\text { VOLA } A_{t s}=R A_{t i}^{2} \frac{\sum_{t=1}^{145} R A_{t t}^{2}}{145}
$$

Las volatilidades anormales de İos activos se promedian en sección cruzada cada día de la ventana de estudio, obteniendo la volatilidad anormal media diaria, $V O L A_{i}=N^{1} \sum_{i=1}^{N} V O L A_{i k}$. Para un análisis más completo, se calculan las volatilidades anomales acumuladas en un periodo $\left(t_{1}, t_{2}\right)$,

$$
V O L A A\left(t_{1}, t_{2}\right)_{i t}=\sum_{t=t_{1}}^{t_{2}} V O L A_{t}
$$

Para contrastar si el evento afecta a la volatilidad de los títulos afectados, se utiliza el test de Boehmer et $\alpha l$. [1991], un test convencional que asume varianza constante entre activos y el test no paramétrico de Signos.

Como medida de robustez de los resultados obtenidos en el análisis de volatilidad, también se mide el impacto sobre el nivel medio de la varianza condicional que el evento podría generar. El uso de variable dummy, para reflejar esta circunstancia, ha sido defendida por estudios previos [Karafiath, 1988, y Abad y Rubia, 2003]. Por ello, definimos İa especificación de la varianza condicional mediante el modelo GARCH $(1,1)^{(15)}$.

$$
\begin{aligned}
& R_{i t}=\alpha_{i}+\beta R_{m e}+h_{i t}{ }^{2 / 2} \eta_{t} \\
& h_{t}=\mu+\lambda_{i} \varepsilon_{l t \cdot 1}^{2}+\gamma_{t} h_{t \cdot t}+\xi_{1} D_{1, t \cdot d}+\xi_{2} D_{2 l+d t} \\
& \varepsilon_{i t}=h_{i t}{ }^{1 / \eta_{\eta}} ; \eta_{i} \text { i.t. } d ., E\left(\eta_{z}\right)=0, E\left(\eta_{t}{ }^{2}\right)=1 ; \varepsilon_{i t} / \Omega_{t}-N\left(0, h_{i t}\right)
\end{aligned}
$$

donde la varianza condicional es $h_{i t}=\operatorname{Var}\left(\varepsilon_{i t} / I_{t-1}\right), \varepsilon_{i t}=h_{i t}{ }^{1 / 2} \eta, \eta_{t}$ es el proceso 1uido blanco gaussiano y $I_{t-1}$ es la información disponible en un periodo anterior; la media de la varianza condicional; las variables binarias $D_{1, k d}$ y $D_{2,++d}$ toman el valor 1 durante distintos días anteriores y posteriores al día del evento, respectivamente; $\xi_{1}$ y $\xi_{2}$ representan la sensibilidad del coeficiente autónomo de la varianza condicional en el periodo de tiempo considerado, y $\varepsilon_{i t}$ es el término de error del modelo.

(15) Diversos estudios muestran que, en el mercado español, éste es el madelo que mejor ajusta las volatilidades dado el 


\subsection{Resultados}

Otra forma de analizar si el evento tiene contenido informativo es medir el cambio en la volatīidad. Los resultados muestran en la Tabla 5, que se produce un cambio de signo negativo en la volatilidad. Concretamente si se atiende a la magnitud del cambio entre el día -2 y 2 se produce una disminución en la volatilidad del $-0,0097 \%$ al $-0,001 \%$, lo que indica una disminución en la incertidumbre en los días en torno al evento.

TABLA 5

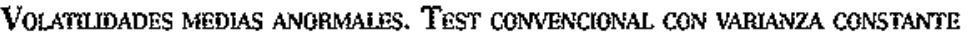
ENTRE ACTINOS, BORHMER Y SIGNOS

\begin{tabular}{|c|c|c|c|c|}
\hline DIA. & VOLA & Var. Cte & Boehmer & Signos \\
\hline $\begin{array}{l}-5 \\
-4 \\
-3 \\
-2 \\
-1 \\
0 \\
1 \\
2 \\
3 \\
4 \\
5\end{array}$ & $\begin{array}{c}0,0001 \\
-0,0001 \\
0,0002 \\
-9,78 \mathrm{E}-05 \\
-1,36 \mathrm{E}-05 \\
-0,0003 \\
-0,0001 \\
-0,0001 \\
-8,47 \mathrm{E}-05 \\
-7,25 \mathrm{E}-05 \\
0,0007\end{array}$ & $\begin{array}{c}0.6528 \\
-2.7519^{* * *} \\
1.2691 \\
-1.8409^{*} \\
-0.0875 \\
-1.5176 \\
-3.6341^{* \star \star} \\
-2.3119^{* \star} \\
-1.4377 \\
-0.7374 \\
1.1782\end{array}$ & $\begin{array}{c}0.2811 \\
-1.2761 \\
1.0312 \\
-0.9795 \\
-0.6427 \\
-0.1192 \\
-1.4605 \\
-1.8267^{\star} \\
-1.5081 \\
-1.3954 \\
0.5695\end{array}$ & 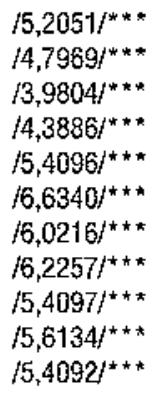 \\
\hline Intervalo & VOLAA & VAR. CTE. & BOEHMER & SIGNOS \\
\hline $\begin{array}{l}(-5,+5) \\
(-2,+2) \\
(-1,+1) \\
(-5,-4) \\
(-5,-3) \\
(-5,-2) \\
(-5,-1) \\
(-4,-3) \\
(-4,-2) \\
(-3,-1) \\
(-2,0) \\
(-1,0) \\
(0,+1) \\
(0,+2) \\
(+1,+2) \\
(+1,+3) \\
(+1,+5) \\
(+2,+3) \\
(+2,+4) \\
(+3,+5)\end{array}$ & $\begin{array}{l}-0,0003 \\
-0,0006 \\
-0,0003 \\
0,0000 \\
0,0003 \\
0,0002 \\
0,0001 \\
0,0001 \\
0,0000 \\
0,0001 \\
-0,0002 \\
-0,0001 \\
-0,0003 \\
-0,0004 \\
-0,0003 \\
-0,0004 \\
-0,0003 \\
-0,0002 \\
-0,0003 \\
0,0000\end{array}$ & $\begin{array}{c}-0,6623 \\
-1,3803 \\
-1,2211 \\
0,0963 \\
0,8146 \\
0,461 \\
0,3891 \\
0,4281 \\
-0,0493 \\
0,4483 \\
-0,9902 \\
-0,6098 \\
-2,5425^{\star * *} \\
-2,9786^{\star * *} \\
-3,618^{\star \star *} \\
-3,2393^{\star \star *} \\
-1,4702 \\
-2,2757^{\star \star} \\
-2,3118^{\star *} \\
-0,0101\end{array}$ & $\begin{array}{c}-0,1828 \\
-0,2176 \\
0,1682 \\
-0,2719 \\
0,4399 \\
0,0966 \\
0,6077 \\
-0,2719 \\
-0,0927 \\
0,7593 \\
0,2769 \\
0,3937 \\
-0,5563 \\
-1,0231 \\
-2,2578^{\star *} \\
-2,3947^{\star * \star} \\
-1,8551^{\star} \\
-2,0026^{\star \star} \\
-2,393^{* \star *} \\
-0,7789\end{array}$ & 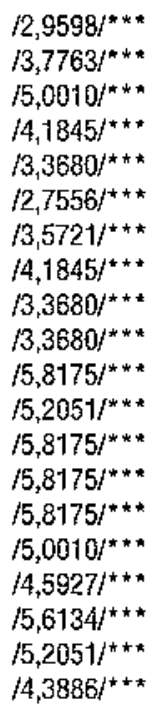 \\
\hline
\end{tabular}

- Significativo al $10 \%$.

** Significativo al $5 \%$.

*** Significativo al $i \%$.

Mediante la utilización de las magnitudes anormales acumuladas podemos ver el efecto de la firma o acuerdo del convenio colectivo a nivel empresa a través de distintas ventanas. Se 
observa el signo negativo y significativo de la volatilidad anormal en las ventanas, $(-2,+2)$ y $(-1,+1)$, siendo menor la disminución de la volatilidad en la ventana $(-2,+2)$ como muestra su valor $-0,06 \%$ significativo al $1 \%$ para Signos. Sólo las ventanas entro el día 0 y el día 4 son significativas para todos los contrastes empleados. Es de destacar que en las ventanas pre-evento antes del día -2 , aparece la volatilidad con signo positivo y significativo para Signos, resultado que coincide con el mayor volumen negociado para los títulos afectados por la firma de un convenio de empresa. Este resultado coincide con el comportamiento del mercado español cuando se examina una serie temporal larga de volúmenes y volatilidades en el que se observa una correlación positiva entre ambas variables. Conforme nos acercamos a la fecha del evento, la volatilidad disminuye como también to haco el volumen negociado.

A continuación para corroborar la validez de los resultados referidos a la volatilidad, se miden cambios en la varianza condicional mediante la estimación del modelo GARCH $(1,1)$ para cada evento, introduciendo dos variables dummy. Por ello, definimos la especificación de la varianza condicional del modelo GARCH $(1,1)$, donde las variabies binarias $D_{1, t \cdot d}$ y $D_{2, t+d}$, toman el valor 1 durante los días anteriores y posteriores al dia del evento o firma del texto articulado del convenio colectivo, para las ventanas $(-5,+5),(-4,+4),(-3,+3),(-2,+2)$ y $(-1,+1)$ días respectivamente. Además hemos realizado un estudio a largo plazo con las ventanas $(-90,+90),(-60,+60)$ y $(-30,+30)$ días.

\section{TABLA 6}

\section{Volatulidad. Modelo Garch $(1, \mathbf{1})$}

Se presenta el número de dummys significativas obtenitas en el modelo Garch $(1,1)$ para el análisis del cambio en la varianza condicional.

\begin{tabular}{|c|c|c|c|}
\hline Ventana & $\begin{array}{c}N^{o} D_{1, t o} \\
\text { significativas }\end{array}$ & $\begin{array}{c}M^{\circ} D_{2, H} \\
\text { significativas }\end{array}$ & Signo \\
\hline $\begin{array}{c}(-90,+90) \\
(-60,+60) \\
(-30,+30) \\
(-5,+5) \\
(-4,+4) \\
(-3,+3) \\
(-2,+2) \\
(-1,+1)\end{array}$ & $\begin{array}{c}7 \\
15 \\
18 \\
38 \\
43 \\
47 \\
59^{* \star \star} \\
66^{* \star *}\end{array}$ & $\begin{array}{c}10 \\
13 \\
14 \\
27 \\
36 \\
36 \\
44 \\
51^{\star \star \star}\end{array}$ & $\begin{array}{l}\text { NEGATIVO } \\
\text { NEGATIVO } \\
\text { MEGATIVO } \\
\text { MEGATIVO } \\
\text { MEGATIVO } \\
\text { MEGATIVO } \\
\text { MEGATIVO } \\
\text { MEGATIVO }\end{array}$ \\
\hline
\end{tabular}

*.. Signiticativo ai 1\%.

Para analizar si existen diferencias significativas en lo que a volatilidad se refiere para un total de 96 eventos, obtenemos el número de variables dummy significativas para cada ventana elegida. La Tabla 6 muestra que conforme disminuimos el tamaño de la ventana de evento, a partir del día -2 y hasta el día +1 existe un cambio en la volatilidad, concretamente de signo negativo. Todas las variables dummy significativas encontradas tienen un nivel de significatividad del $1 \%$. La reducción de la volatilidad tras el evento supone que la nueva información reduce, pero sólo a corto plazo, la incertidumbre que sobre la evolución de los beneficios de la empresa tienen los inversores.

Se puede concluir que la liegada de nueva información sobre İas relaciones İaborales al mercado bursátil español produce una disminución en la volatilidad específica del mismo, 


\section{DETERMINANTES DE LA RESPUESTA DEL MERCADO AL ANUNCIO DEL CONVENIO COLECTIVO}

\subsection{ANÁlISIS DESCRIPTIVo}

En la Tabla 7 se han clasificado y ordenado los distintos eventos el día cero de mayor a menor rentabilidad anormal y también por sectores. En esta Tabla se presentan, por grupos, la rentabilidad, volumen, volatilidad anormal y la variación en los gastos de personal que experimentan las empresas de la muestra como consecuencia del evento, entre el año anterior y el año del convenio. Se ha de tener en cuenta que los efectos del convenio tienen carácter retroactivo para todo el año del acuerdo, es decir, sus efectos se aplican a todo el año independientemente del momento en que se firme.

Esta misma variación se ha calculado controlando por el número de empleados ${ }^{\text {(16) }}$. Para cada grupo de empresas se calcula la media del tamaño meảido como la capitalización del mercado y del número de empleados contratados el año del convenio. También se ha atendido a la productividad en esta ocasión, lógicamente si la subida salarial viene acompañada de una mayor productividad, el convenio no tiene por qué tener ningún efecto sobre los futuros fiujos de caja de la empresa. Para controlar este hecho se ha estudiado el texto de cada convenio y se han clasificado las empresas en aquellas que en el convenio exigen un aumento en la productividad, (de todas las encontradas ninguna fijaba un porcentaje de aumento determinado), aquelias que incentivan a sus empleados para conseguir ese aumento a través de complementos de productividad o pluses por objetivos pero que en ningún caso tienen el carácter de vineulante y aquellas otras compañías que obvian por completo en el convenio el tema de la productividad. En la Tabla 7 se muestra el porcentaje de empresas que poseen cláusula de productividad.

\section{TABiA 7}

\section{DETERMINANIES DEL CONVENO Y VARIABiES FINANCIERAS}

En la siguiente Tabla se observa en media, la rentabilidad, volumen y volatilidad anormal el día cero de los 96 eventos ordenados de mayor a menor rentabilidad y por sectores, variación de los gastos de personal y del ratio coste de personal por empleado, tamaño, número de empleados y porcentaje de convenios con cláusulas de productividad.

\begin{tabular}{|c|c|c|c|c|c|c|c|c|}
\hline EvENTO & RA & $V A$ & VOLAA & V. GP & V. RATIO & TAAAANO & EMPLEO & PRo.C \\
\hline Grupo 1 & $-0,0342$ & 0,3470 & 0,0010 & 0,0850 & 0,0618 & 2808,5 & 10850,7 & 0,6 \\
Grupo 2 & $-0,0148$ & $-0,1896$ & $-0,0002$ & $-0,0421$ & 0,0757 & 1111,0 & 5291,6 & 0,4 \\
Grupo 3 & $-0,0088$ & 0,5037 & $-0,0003$ & 0,0729 & $-0,0187$ & 3177,3 & 11896,3 & 0,4 \\
Grupo 4 & $-0,0057$ & 0,7720 & $-0,0005$ & 0,0397 & 0,0555 & 2977,3 & 9399,4 & 0,3 \\
Grupo 5 & $-0,0024$ & 0,0307 & $-0,0002$ & 0,2270 & 0,0284 & 1030,7 & 4479,4 & 0,5 \\
Grupo 6 & $-0,0003$ & 1,3916 & $-0,0002$ & 0,0984 & 0,1521 & 13120,9 & 27420,1 & 0,4 \\
Grupo 7 & 0,0024 & 0,2556 & $-0,0002$ & 0,1618 & 0,0832 & 14675,8 & 31220,2 & 0,7 \\
Grupo 8 & 0,0071 & 0,2340 & $-0,0004$ & 0,0451 & 0,0289 & 3590,5 & 5423,0 & 0,3 \\
Grupo 9 & 0,0134 & 0,1545 & $-0,0002$ & 0,1863 & 0,2776 & 5161,5 & 11226,9 & 0,5 \\
Grupo 10 & 0,0269 & 1,1985 & 0,0003 & 0,9745 & 0,4195 & 2750,9 & 6142,3 & 0,66 \\
\hline
\end{tabular}




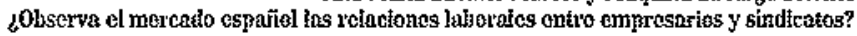

\section{TABLA 7 (Cont.)}

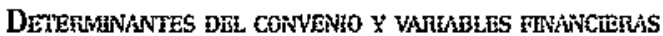

\begin{tabular}{|c|c|c|c|c|c|c|c|c|}
\hline SECTOR & $R A$ & VA & VOLAA & VA GP & V. RAHO & TAAAASO & EAAPLO & P AO. $C$ \\
\hline IO & $-0,0105$ & 2,1524 & $-0,0001$ & 0,0301 & 0,0718 & 1118,4 & 1175,5 & 0 \\
CYOS & $-0,0023$ & $-0,3469$ & $-0,0003$ & 0,1538 & 0,0277 & 386,9 & 12819,3 & 0,33 \\
CVMG & 0,0065 & 0,3801 & $-0,0001$ & 0,0196 & 0,0464 & 525,4 & 2710,4 & 0,2 \\
I & 0,0011 & $-0,6674$ & $-0,0003$ & 0,0240 & 0,0330 & 46,2 & 1042,0 & 1 \\
OIT & 0,0005 & 0,3732 & $-0,0003$ & 0,2520 & 0,0544 & 1206,8 & 6183,6 & 1 \\
TYC & $-0,0020$ & $-0,1845$ & $-0,0002$ & 0,4668 & 0,3658 & 19155,8 & 37692,2 & 0,62 \\
EYA & $-0,0072$ & 0,2897 & 0,0003 & 0,0713 & 0,0398 & 5499,3 & 9096,0 & 0,33 \\
FINAN & 0,0000 & 0,5996 & $-0,0000$ & 0,2342 & 0,2300 & 21412,3 & 35587,4 & 0,4 \\
MB & $-0,0202$ & $-0,0371$ & 0,0001 & 0,0650 & 0,0550 & 1126,3 & 16073,0 & 1 \\
TM & 0,0069 & 1,9500 & $-0,0002$ & 0,0674 & 0,0642 & 1575,5 & 4424,2 & 0,73 \\
NT & $-0,0118$ & $-0,0925$ & $-0,0004$ & 0,0493 & 0,0961 & 307,5 & 2398,0 & 0,11 \\
\hline
\end{tabular}

RA: Rentabllidad Madia Anormal. VA: Volumen Medlo Anormal. VotaA: Volatilldad Bedia Anormal. Varlacion GP. (Gastes personal t -Gasios personal t-1)/ Gastos personal t-1; Varlacion Ratlo: (Gastos personal t $n n^{\circ}$ empleados $t-G a s t o s$ personal t-t/n.9 empleados

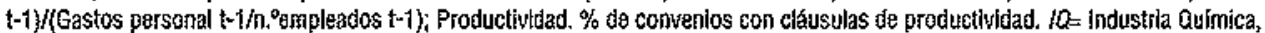
cYOS= Comerclo y Otfos Servicios, CVMG= Cemento, Vidrio y Materiales de Construcclón, $k$ inmobiliarias, OlT= Otras industrias de Transiormación, $T Y G=$ transportes y Comunicaciones, EYA= Energia y Agua, FHAN= Financieras, MB= Mugtálicas Básicas, TM= Transformaclón de Mletales, NT= Nuevas Tecnologias.

Si observamos el panel superior de esta Tabla, en el que las empresas se han clasificado según su rentabjilidad anormal, vemos que, de forma general, se produce un aumento en el volumen negociado y una caída en la volatilidad especifica en el día cero. Esto significa que cuando el anuncio llega al mercado provoca mayores presiones de venta y rentabilidades anormales negativas para estos grupos, El resultado discrepa del observado en el mercado español entre volumen y volatilidad, pero se ha de tener en cuenta que se está midiendo el impacto del contenido informativo de un evento en un día concreto, si se observa la Tabla 4 y 5 , los resultados muestran que el volumen disminuye a partir del día -2 al igual que lo hace la volatilidad, cumpliéndose por tanto la correlación positiva que existe entre ellas cuando se analiza una serie histórica.

En la mayoría de los casos se produce en media un aumento en los gastos de personal como consecuencia del convenio que oscila entre un $0,5 \%$ a un $97 \%$. Si atendemos al aumento experimentado en el salario por empleado, se observa que la mayoría de trabajadores de las empresas que pasan a tener convenio propio, experimentan un incremento salarial entee un $2 \%$ y un $41 \%{ }^{[77}$. Lógicamente aquellas empresas que presentan menores costes laborales y una mayor ganancia por empleado, se debe a una reducción importante en el número de empleados. Además se observa que las empresas más grandes y con mayor número de empleados, son las que sufren una menor variación en la rentabilidad de sus acciones corno consecuencia de la firma del convenio.

En cuanto a la productividad, las empresas que en el convenio estipulan un aumento vinculante para sus empleados, deberían ser menos penalizadas por el mercado, ya que como hemos comentado el aumento en los costes laborales se vería compensado. En este panel superior, observamos que la penalización por el mercado no se corresponde con la productividad negociada. 
Respecto al análisis por sectores (panel inferior de la Tabla 7), se observa que existe un claro efecto sector; que en ocasiones es independiente del contenido del convenio. Son los sectores Metálicas Básicas y Nuevas Tecnologías los más castigados por el mercado, aunque este resultado no se corresponde con una mayor subida salarial por empleado ni con la ausencia de cláusulas de productividad en el convenio. Curiosamente, para estos dos sectores, también el volumen negociado anormal es negativo. Sin embargo, en el caso de Industria Química, es claro que la firma del convenio provoca una venta masiva de los títulos (el volumen anormal es mayor mientras que la rentabilidad es menor). De hecho, éste es el sector en el que ninguna de las empresas incluye en el convenio referencia alguna sobre la productividad exigida a sus empleados. En el caso contrario están las empresas de Transformación de Metalies, para las que observamos incrementos en el volumen negociado acompañados de incrementos en los precios de sus acciones. En este sector, el incremento en los gastos por empleado es relativamente pequeño y en un $73 \%$ de los convenios de empresa firmados por empresas de este sector se establecen incentivos a la productividad. Por tanto, parece que, para algunos sectores, las características del convenio sí son tenidas en cuenta en la valoración que hace el mercado de sus empresas. Los diferentes resultados por sectores, ponen de manifiesto, tal y como argumenta Chae [2002], que en cada sector existe un grado de asimetría infomativa distinto, de ahí que la información se interprete de diferente forma y en periodos de tiempo distintos ${ }^{\mid 181}$.

\subsection{Factores determinantes de das Magntudees dei MERcado alrededor}

de la Firma del Convenio de Empresa

Una vez demostrado que el mercado de capitales español observa las relaciones laborales, y que este hecho está relacionado con cambios negativos en el rendimiento anormal de la empresa y positivos sobre el volumen anormal, resulta interesante examinar la posible existencia de determinadas características de la empresa y del convenio que explican dichos cambios. Para ello, se regresan la Rentabilidad Anormal ( $R A A$ ), Volumen Anormal (VAA) y Volatilidad Anormal (VOLAA) acumulada en la ventana $(-2,+2)$ sobre dichas variables, como indica la ecuación 12, considerando también estas variables anormales como variables explicativas ${ }^{(19)}$.

$$
\begin{array}{r}
\text { RAA/VAA/NOLAA } A_{i}=\sum_{i=1}^{11} \beta_{k} \cdot \operatorname{Sec}_{i}+\beta_{12} \cdot \text { Tamaño }_{i}+\beta_{13} \cdot \text { Resultado }_{i}+\beta_{14} \cdot \text { Empleo }_{i}+ \\
\beta_{15} \cdot \text { Varatio }_{1}+\beta_{16} \cdot \text { ProducC }_{i}+\beta_{17} \cdot \text { TCS }_{i}+\beta_{18} \cdot \text { Sorpresa }_{i}+\beta_{19} \cdot R A A / V A A / \text { NOLAA }_{i}+\mu_{i}
\end{array}
$$

Siendo $S e c_{i}$ los sectores Industria Química, Comercio y Otros Servicios, Cemento, Vidrio y Materiales de Construcción, Inmobiliarias, Otras Industrias de Transformación, Transportes y Comunicaciones, Energía y Agua, Financieras, Metálicas, Transformación de Metales, Nuevas Tecnologías.

Con este análisis, se trata de deteminar qué características de las empresas de la muestra que firman un convenio colectivo a nivel empresa, influyen en las magnitudes anormales observadas en la ventana de evento.

(18) En este caso sólo se atiende al dia del eventa, por lo que cabe la posibilidad de que el inversor reaccione dias antes debido a la noticia de un preacuerdo en el convenio.

(19) La elección de la ventana $(-2,+2)$ se basa en los efectos significativos encontrados para las variables analizadas rentabilidad, volumen y volatilidad anormales en dicho periodo. 
Empíricamente, para el caso español, se ha contrastado que las empresas más grandes tienen una probabilidad mayor de acometer una negociación colectiva inteina Uumeno y Rodríguez, 19961. Para estas empresas suele ser menos importante la comparación de los costes laborales de las empresas que concurren en su mismo mercado. No afecta de forma tan intensa a la posición de las empresas on el mercado que obras asuman un coste menor, pues sus propias condiciones económicas les permiten soportar un coste más elevado sin tener que reflejarlo o tasiadarlo al precio de sus productos. Por otro lado, la casi siempre menor complejidad de la empresa pequeña hace que sea fundamental el coste del tabajo y, por ello, fundamentales también las condiciones de trabajo pactadas. En la muestra tratamos de comprobar el efecto del tamaño sobre las magnitudes anomales observadas en torno a la fecha del evento. El signo espexado a priori enire tamaño y rentabilidad anormal es positivo siendo, las empresas más grandes las menos castigadas por el mercado debido, por ejemplo, a la mayor cantidad y calidad de la información que suministran al mercado [Lang y Lundholm, 1993]. El mismo razonamiento se puede aplicar para el resultado del ejercicio, aquelias empresas que obtienen mejores resultados contables deberían estar menos penalizadas por los inversores.

La variable tamaño también ha sido utilizada en numerosos estudios de volúmenes como determinante de los mismos ante un evento conereto, como por ejemplo, el anuncio de beneficios. Trabajos como el de Chae [2002] considera el tamaño y los distintos sectores a los que pertenecen las empresas de la muestra como proxy de información asimétrica.

Además se incluyen como variables explicativas en el modelo las consecuencias más inmediatas que se desprenden del convenio, como la vaziación en el coste de personal por empleado, la tasa de cobertura sindical o número de trabajadores cubiertos por convenio y la inclusión de cláusulas de productividad medido a través de una variable dicotómica que toma el valor 1 si la empresa incluye cualquier tipo de cláusula de productividad a través por ejemplo de complementos o pluses. Se espera, si el inversor atiende al contenido del convenio, que aquelias empresas con mayor subida salarial, que no incluyen cláusulas de productividad en el convenio, con mayor número de empleados y presencia sindical (medida por la tasa de cobertura sindical), sean más penalizadas por el mercado.

También se mide el impacto de la parte no esperada del ineremento salarial sobre los cambios en las magnitudes anormales. A priori y a tenor del trabajo de Abowd [1989] que mide el impacto de los shocks no anticipados en costes salariales sobre la riqueza del accionista, esperamos que la relación entre rendimientos anormales y esta variable sea negativa, es decir; se espera que cuando la solpresa sea mayor los tútulos sean más penalizados por el inversor.

La inclusión de dummys sectoriales es particularmente importante ya que indican de forma individualizada en qué sector es más importante el ef́ecto de la firma de un convenio de empresa en términos bursátiles. Se han creado tantas dummys como sectores. El criterio tenido en cuenta para la clasificación de las entidades por sectores ha sido el establecido por la Comisión Nacional del Mercado de Valores. La clasificación consta de once sectores. Bn la Tabla 1 se indica la distribución por sectores de las empresas de la muestra y de las empresas competidoras pertenecientes al mercado continuo.

Un análisis previo de la matiz de correlaciones entre las variables, muestra la presencia de cierta raulticolinealidad, cuyo impacto sobre los resultados finales se limita seleccio- 
el modelo constituyen diferentes combinaciones de las variables de la empresa, biseñadas para solventar colectivamente el problema de multicolinealidad.

Asimismo, el contraste de homocedasticidad mediante el test de White permite aceptar la hipótesis nula de igualdad de varianzas de los residuos. El test de Jarque-Bera facilita la contrastación de la normalidad de los residuos, demostrando la existencia de la misma. Sin embargo, el test de Durbin-Watson acepta la existencia de autocorrelación de los residuos de orden 1. En consecuencia la estimación se efectúa por $M C O$ teniendo en cuenta que los grados de significación de los coeficientes se han determinado a partir de las matrices de varianzas-covarianzas robustas a formas generales de autocorrelación de Newey-West ${ }^{(20)}$.

La Tabla 8 resume los resultados de las regresiones de corte trasversal. El coeficiente $R^{2}$ se sitúa en tomo al 23-27\%, es decir, las variables independientes del modelo explican un porcentaje relativamente aceptabie de la variabilidad de la variable endógena. En cuanto a la significatividad conjunta de las variables explicativas del modelo los test permiten conclui;; en todas las ecuaciones, que se obtiene información significativa al introducir características de la empresa.

Cuando sólo se incluyen las dummy que diferencian por sectores, el único sector cuyas rentabilidades se ven afectadas significativamente de forma negativa por la firma del convenio es Comercio y Otros Servicios. En cuanto al volumen, observamos incrementos significativos en el caso de Industria Química y caídas en Nuevas Tecnologías. Los resultados son coherentes con los presentados en la Tabla 7 . El efecto del convenio sobre los rendimientos se acentúa cuando incorporamos en la regresión variables relacionadas con las características de la empresa o del convenio. En este caso, los rendimientos anormales acumulados son negativos en todos los sectores y significativos en seis de ellos.

El signo de las variables tamaño y resultado del ejercicio en relación con la rentabilidad anomal acumulada es el esperado. El inversor penaliza en menor medida a las empresas más grandes y que obtienen mayores beneficios. En cambio, respecto a la volatilidad anormal, son las empresas más grandes las que presentan menor cambio en dicha variable. También se observa que el volumen anormal acumulado explica, a un nivel de significatividad del $10 \%$, cambios de signo positivo en la rentabilidad anormal, es decir, a mayor volumen negociado el impacto sobre el precio es menor en la ventana $(-2,+2)$, recordamos que los mayores volúmenes se producen antes del día -2, a partir de entonces y hasta el día del evento el mercado alcanza el consenso, hecho reflejado en menores precios y menores volúmenes negociados. Se observa también la relación positiva y significativa entre volumen y volatilidad.

El resto de variables asociadas al contenido del convenio, tal y como se observa en la Tabla 8, no afectan de forma significativa a las magnitudes anormales que reflejan la reacción del mercado ante el anuncio del evento, lo que quiere decir; que el inversor no atiende a las particularidades propias del convenio. Hecho que se corrobora con la falta de significatividad en la variable sorpresa, que mide el impacto de la componente no esperada de la prima salarial que subyace a la negociación. 
TABLA 8

Determinantes de Rentablidades. Volúaenes y Volatilidades ANormates. Ventana (-2,+2)

Se presentan ios resultados del análisis de regresión con el que se pretente anaitizar qué factores pueden ser consizerados explicativos de los cambios en las magnitudes anormales para la ventana $(-2,+2)$

\begin{tabular}{|c|c|c|c|c|c|c|c|c|c|c|c|c|}
\hline & \multicolumn{4}{|c|}{$R A A$} & \multicolumn{4}{|c|}{$V / A A$} & \multicolumn{4}{|c|}{ VOLAA } \\
\hline 10 & -0.008 & -0.003 & & & 0.407 & $0.924^{\star}$ & & & -0.000 & -0.0002 & & \\
\hline cYos & $-0.013^{* \star}$ & $-0.005^{* *}$ & & & -0.320 & 0.033 & & & -6.0003 & $-0.0003^{* *}$ & & \\
\hline CVMG & -0.010 & 0.0002 & & & -0.879 & -0.486 & & & -0.0000 & -0.0001 & & \\
\hline i & $-0.137^{\star}$ & -0.007 & & & -0.730 & -0.360 & & & -0.0002 & -0.0602 & & \\
\hline OIT & -0.009 & -0.0002 & & & -0.264 & 0.169 & & & -0.0002 & -0.0001 & & \\
\hline TYC & $-0.015^{ \pm \star}$ & -0.001 & & & -0.737 & -0.241 & & & -0.0001 & -0.0000 & & \\
\hline EYA & $-0.011^{*}$ & -0.0002 & & & -0.317 & 0.238 & & & 0.0001 & 0.0001 & & \\
\hline FINAN & $-0.016^{\star}$ & -0.002 & & & 0.251 & 0.602 & & & 0.0001 & 0.0000 & & \\
\hline$M B$ & $-0.0 j 42$ & $\cdot-0.003$ & & & -0.881 & -0.322 & & & -0.0002 & -0.0001 & & \\
\hline $\mathrm{TM}$ & -0.009 & 0.0005 & & . & -0.243 & 0.226 & & & -0.0002 & -0.0002 & & \\
\hline$N T$ & $-0.012 * *$ & -0.002 & & $\cdot$ & -0.405 & $-0.778^{\star x}$ & & & -0.0003 & $-0.0004^{\star \star \star}$ & & \\
\hline TAMAÑO & $0.002^{\star}$ & & $0.002^{* * *}$ & & 00.134 & & -0.012 & & 0.0000 & & $0.0002^{\star}$ & \\
\hline RDO & & & & $0.002^{* *}$ & & & & 0.023 & & & & 0.0001 \\
\hline EMPLEO & 0.0005 & & -0.0005 & & 0.007 & & 0.019 & & -0.000 & & -0.0000 & \\
\hline VARATIO & 0.0052 & & & & -0.263 & & & & -0.0004 & & & \\
\hline PRODUC.C & 0.0005 & & -0.0000 & 0.001 & 0.249 & & 0.220 & 0.119 & 0.0002 & & 0.0001 & 0.0001 \\
\hline TCS & 0.0000 & & 0.0009 & 0.002 & -0.197 & & -0.232 & -0.140 & -0.0001 & & -0.0003 & -0.0000 \\
\hline SORPRESA & & & -0.0000 & & & & -0.001 & & & & -0.0000 & \\
\hline RAA & & & & & & & $27.18^{*}$ & $27.00^{*}$ & -0.0013 & & -0.012 & -0.007 \\
\hline VAA & & & $0.001^{*}$ & $0.001 *$ & & & & & 0.000 & & 0.0000 & $0.0000^{*}$ \\
\hline VOLAA & -1.373 & & -1.058 & -0.794 & 4.069 & & 63.66 & $102.16^{*}$ & & & & \\
\hline
\end{tabular}

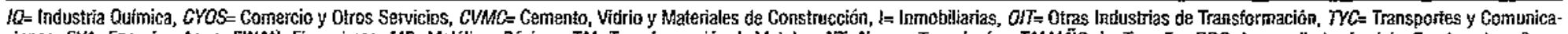

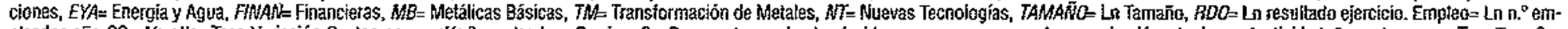

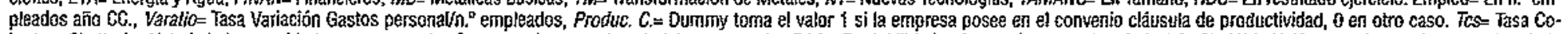
bertura Sindical o \% trabajadores cubiertos por convenio. Sorpresa- incremento salarial no esperado. RAA = Rentabilidades Andrmales para el periodo (-2, +2$)$. VAA= Volümenes Anosmales para el periode $(-2,+2)$. VOLAA $=$ Votatitidad Anormai periodo $(-2,+2)$.

* Significativo al $10 \%$.

** Significativo al $5 \%$. 


\section{CONCLUSIONES}

Entendiendo que la firma de un convenio colectivo interprovincial y a nivel de empresa podría tener consecuencias sobre la valoración que hacen los inversores de las acciones de las empresas que lo firman, en este trabajo intentamos analizar las consecuencias que este evento tiene sobre tres variables: la rentabilidad anormal, el volumen negociado anormal y la volatilidad especifica en los dís cercanos a la tirma de tales convenios, para empresas que cotizan en el mercado español.

El análisis de movimiento del precio de las acciones, volumen negociado y volatilidad alrededor del evento, mediante la estimación de las magnitudes anormales, pone de manifiesto que, en términos medios, la noticia de la firma de un convenio de empresa tiene contenido informativo y es interpretada de forma negativa por el mercado. Encontramos volúmenes negociados anormalmente altos en las fechas previas al día del anuncio del convenio, mostrando la heterogeneidad en las expectativas de los inversores, que persisten en menor magnitud acompañados de rendimientos anormalmente bajos más cerca de la fecha del acontecimiento. Por tanto, podemos concluir que los inversores allcanzan el consenso cuando éstas firman el convenio. Por otro lado, la volatilidad específica de estos títulos disminuye, lo que indicaría que la información aportada por la firma del convenio no tiene carácter de sorpresa, sino que puede interpretarse como una reducción en la incertidumbre que los inversores tienen a cerca de los flujos futuros de las empresas dado que algunas magnitudes que conforman estos llujos quedan perfectamente establecidas en el convenio.

Además, mediante un análisis de corte transversal, encontramos que existen diferentes reacciones dependiendo del sector al que pertenezcan las empresas, y que la pérdida de valor es mayor para las empresas más pequeñas y con menores beneficios. Sin embargo, no encontramos relaciones significativas entre la reacción del mercado y determinadas características del convenio, como el incremento en los gastos por empleado o los incentivos a la productividad.

\section{APÉNDICE: NATURALEZA DE LA NEGOCIACIÓN COLECTTVA EN ESPAÑA}

La Constitución en su artículo 37.1 establece que: «La Ley garantizará el derecho a la negociación colectiva laboral entre las representantes de los trabajadores y empresarios, así como la fuerza sindical vinculante de los convenios.»

Aunque es la Constitución la que garantiza el derecho a la Negociación Colectiva, el mismo se desarrolla en el Estatuto de los Trabajadores. Concretamente, el artículo 82.2 dice: «Mediante los Convenios Colectivos y en su ámbito correspondiente, los trabajadores y empresarios regulan las condiciones de trabajo y de productividad; igualmente podrán regular la paz laboral a través de las obligaciones que se pacten».

Un convenio colectivo se puede definir como un acuerdo escrito, libremente negociado entre los representantes de los trabajadores y de los empresarios, para regular las condiciones de trabajo y normas de convivencia laboral en las empresas. Los convenios colectivos regulan materias de índole económica, laboral, sindical, asistencial, y en general, cuantas afecten a las condiciones de empleo y al ámbito de las relaciones de los trabajadores y sus organizaciones representativas con el empresario y las asociaciones empresariales. Son materias vinculantes para las partes, y las condiciones pactadas 
no podrán ser modificadas por contrato individual, salvo para mejorarłas. El Estatuto de los trabajadores señala dos ámbitos diferentes, convenios de empresa o de ámbito inferior y convonios de ámbito superior a la empresa (sector).

La tramitación de un convonio colectavo distingue varias fases sucesivas. Las más importantes son las que se enuncian a conlinuación:

1. Iniciación de la Negociación. - Los representantes tanto de los tiabajadores como de los empresarios que promuevan la negociación, lo comunicarán por escrito a la otra parte, expresando detalladamente su legitimación, los ámbitos del convenio y las materias objeto de negociación. Se enviará una copia de esta propuesta de negociación a la autoridad laboral correspondiente en función del ámbito territorial del convonio. En el plazo máximo do un mes, a partir de la recepción de la comunicación, la otra parte debe responder a la propuesia do negociación, con lo que ambas partes podrán ya establecor un calendario o plan de negociasión. La parte receptora puede negarse a negociar si existe alguna causa legal o cuando so trate de revisar un convenio que no ha vencido.

2. Negociación.-Ambas partes están obligados a negociar bajo el principio de buena fe, es decir, a no utilizar engaños ni intimidaciones y a proporcionar toda la información necesaria. En cualquier momento de las deliberaciones, las partes podrán acordar la intervención de un mediador designado por ellas.

Para que los acuerdos de la comisión negociadora sean válidos, es necesario el voto favorable de la mayoria de cada una de las partes negociadoras. Si İa negociación thaliza con acuerdo, el convenio se registrará y publicará. Si la negociación finaliza sin acuerdo, se prorrogará el convenio anterior, pero sólo se mantiene en vigor el contenido normativo (dorechos y obligaciones de las partes, condicionos de trabajo, clasiffcación de puestos de trabajo, promoción profesional, salarios, tiempo de trabajo, etc.) y pierde su vigencia el contenido de obligaciones (proceso de denuncit, compromiso de garantizar la paz laboral ai renunciar los trabajadores al derecho a la huelga durante el periodo de vigencia del convenio, etc.).

3. Registro y depósito.-Dado el carácter de noma escrita que téne el convenio, ta comisión procede al registro y depósito ante la autoridad laboral competente dentro del plazo de quince días a partir de la fecha en que ambas partes lo firman. Una vez registrado se enviará, para su depósito, al Servicio de Mediación, Arbitraje y Conciliación (SMAC, o al brgano correspondiente de la Comunidad Autónoma cuando esta materia está transferida. Si la autoridad laboral estimase que el convenio colectivo vulinera alguna norma iegal, no lo aprobará, y se limitark a registrarlo y a enviarlo al juzgado de lo Social para que éste decida.

4. Publicación y entrada en vigor-En el plazo máximo de diez días desde la presentación del convenio en el registro, la autoridad laboral disponỏrá su publicación obligatoria y gratuita en el $B O E$ o en el $B O P$ a çue corresponda, dependiendo del ámbito territorial el convenio. Los convenios publicados en el $B O E$ serán aplicados por los jueces y tribunales sin necesidad de alegar y probar su existencia. El convenio entrará en vigor on la fecha que acuerden las partes.

5. Duración de los convenios colectivos. - Las partes negociadoras establecen la duración de los Convenios Coloctivos. No obstante, se pueden pactar disủntos periodos de vigencia para cada materia o grupo homogéneo de materias dentro del mismo convenio; por ejemplo, la duración fijada para el convenio puede ser de tres años, pero con revisión anual de los salarios de acuerdo con el IPC. Salvo pacto en contra, los convenios colectivos se prorrogarán de año en año si no medila denuncia expresa de las partes.

\section{BIBLIOGRAFÍA}

ABAD, D., y RuBiA, A. [2003]: «Liqułdez, volatilidad y rendimiento en el sistema fixing español: Una evaluación empíricas, Moneda y Crédito, Vol. 217, pp. 45-72. 
ATIASE, R., y BAMBER, L. [1994]: «Trading volume reactions to annual accounting earnings announcements», Joumal of Accounting an Economics, 17, pp. 309-329.

BAILEY, W.; KAROAY, G. A., y SALA, Y. C. [2002]: «The economic consequences of increased disclosure: evidence from international cross-listings, Working paper, Cornell University.

BALL, R., y BRowN, Y. P. [1968]: «An empirical evaluation of accounting income numbers», Journal of Accounting Research, Vol. 6, pp. 159-178.

BAMBER, L. S. [1986]: «The information content of annual eamings releases: A trading volume approachs, Journal of Accounting Research, Spring, pp. 40-56.

- [1987]: «Unexpected earnings, firm size, and trading volume around cuarterly earnings announcements», Accounting review, Vol. 62, pp. 510-532.

— , y CuEON, Y. [1995]: «Differential price and volume reactions to accounting earnings announcements», Accounting Review, Vol. 70, pp. 417-441.

BÁRCENA, J. C., y INURRETA, A. [1997]: «La Negociación Colectiva en la Europa Continental: Aproximación al caso Español», Documentos de Trabajo, BuTOKL.

BEAVER, W. H. [1968]: «Financial Reporting: An Accounting Revolution», Englewood Cliffs, Prentice Hall, New Jersey.

Bofiner, E.; Musumeci, J., y Pousen, A. [1991]: «Event-Study Methodology Under Conditions of EventInduced Variance», Journal of Financial Economics, Vol. 30, pp. 253-272.

Bronars, S., y DeERe, R. [1991]: «The Threat of Unionization, the Use of Debt and the Preservation of Shareholder Wealth», Quarterly Journal of Economics, Vol. 106, pp. 231-254.

- [1994]: «Unionization and Profitability: Evidence of Spillover Effects», Journal of Political Economy, Vol. 106(6), pp. 1.281-1.287.

BROWN, C.; HARtow, W. W., y Tinc, S. [1988]: «Rissk Aversion, Uncertain Information and Market Efficiency», Journal of Financial Economics, Vol. 22, pp. 355-385.

CHAE, J. [2002]: «Timing information, information asymmetry, and trading volume», Working paper, M.I.T. Sloan School of Management.

CLARK, K. [1980]: «The impact of Unionization on Productivity: A Case Study», Industrial and Labor Relations, Vol. $33, \mathrm{pp} .451-469$.

- [1984]: «Unionization y Firm Performance: The Impact on Profits, Growth and Productivity», American Economic Review, Vol. 74, December, pp. 893-919.

Conouy, R.; HInsch, B., y Hinsadey, M. [1986]: «Union Rent Seeking, Intangible Capital, and Market Value of the Firm》, Review of Economics and Statistics, Vol. 68, January, pp. 567-577.

Cirlinan, C. P., y KnosLETT, J. A. [1994]: «Unionization and Accounting Policy Choices: An Empirical Examinations, Journal of Accounting and Public Policy, Spring, pp. 49-78.

DALMAZO, A. [1992]: «Wage Negotiations and Capital Structure: A Strategic Nash Bargaining Approach», London School of Economics, D. P., n. ${ }^{\circ} 91$.

DEANGLEO, H., y DEANGELO, L. [1991]: «Union negotiations and corporate policy», Journal of Financial Economics, November, pp. 3-43.

FAMA, E.; FisHER, L.; JENSEN, M., y RoL, R. [1969]: «The adjustment of stock prices to new information», International Economic Revieu, Vol. 10, pp. 1-21.

INuß\}!ietA, A. [1997a]: «Negociación Colectiva y Valor Bursátil de las Empresas», Mimeo.

- [1997b]: «Internaliza el raercado bursátil español las relaciones laborales: Evidencia Empúrica a partir de un Event-Day Study», Mimeo,

- [1997]: «Negociación colectiva, Rentabilidad Bursátil y Estructura de Capitai en España», Tesis Doctoral. 
JMENo, J. F, y Ronntuaz, D. [1996]: «Wage Drift in Collective Bargaining at Firm Level», Annales D'Economie et de Statisque, Vol. 41/42, pp. 188-205.

Karariatr, I, [1988]: «Using Dummy Variables in the Event Mothodology», The Financial Review, Vol. 23(3).

- [1994]: «0n the Efliciency of Least Squares Regression with Security Abnormol Rotums as the Dependent Variable», Journal of Financial and Quantitative Analysis, Vol. 29, pp. 279-300.

KARPOF, J. M. [1986]; «A Theory of Trading Volume», The Journal of Finance, Vol. 5.

KIM, O., y VERnECCHA, R. E. [1991a]: «Trading volume and price roaction to public announcements», Journal of Accounting Research, Vol. 29.

Kross, W.; HA, G., y HERLN, F. [1994]: «A test of risk clientele ellects via an examination of trading volume response to earnings announcements», Journal of Accounting and Economics, Vol. 18, pp. 67-88.

LaNG, M. H., y LiNDHotm, R. J. [1993]: «Cross-Sectional Determinants of Analysts Ratings of Corporate Disclosures», Joumal of Accounting Research, Autumn, pp. 247-271.

LIBERTY, S. E., y ZMMMRMMN, J. L. [1986]: «Labol union contract negotiations and accounting choices», The Accounting Review, October; pp. 692-712.

Monssma, M. [1991b]: «information sharing and Collective Bargaining in Japan: Effects on wage negotiationy, Industrial and Labor Relations Review, April, pp. 469-485.

MorsE, D. [1981]: «Price and trading volume reaction surrounding earnings announcements: A closer examination», Journal of Accounting Research, Autumn, Vol. 19, n. ${ }^{\circ} 2$.

NeuMANN, G. [1980]: «The predictability of strikes: Evidence from the Stock Market», Industrial and Labor Relations, Vol. 33, pp. 525-535.

NicoiAu, J. L. [2001]: «Parametric and no parametric approaches to event studies: an application to a hotel's market value», Working paper IVE, WP-AD 2001-08.

NickBL, S., y WADIHWANI, S. [1988]: «Unions, Wages and Employment. Tests Based on U.K. Firm-Level Datas, European Economic Review, Vol. 32. pp. 727-733.

Ptrenson, P. [1989]: «Event Studies: A review of issues and methodology», Quarterly Journal of Business and Economics, Vol. 28, pp. 36-66.

RuN, R., y TAssun, R. J. [2004]: «Are economically significant stock returns and trading volumes driven by firm-specific news relonses?n, Journal of Business Finance and Accounting 31(1), 49-82.

RUBACK, R., y ZGMABMAN, M. B. [1984]; «Unionization and Profitability: Evidence from the CapitaI Market», Journal of Political Economy, Vol. 92(6), pp. 1.134-1.155.

SALNGER, M. [1984]: «Tobin's q Unionization, and the Concentration-Profits Relationship», Journal of Economics, Vol. 15, pp. 159m170.

Sciwenr, G. [1981]: «Using Financial Data to Measure Effects of Regulation», Journal Law and Economics, Vol. 24, pp. 121-158.

YAMAI, H. [1986]:«Collective bargaining and accounting disclosure: an incuiry into the changes in accounting policym, International Joumal of Accounting Education Research, Fall, pp. 11-23. 